\title{
Insights into secondary reactions occurring during atmospheric ablation of micrometeoroids
}

Richard W. Court ${ }^{*}$ and Jonathan Tan

Impacts and Astromaterials Research Centre, Department of Earth Science and Engineering, Imperial College, London, SW7 2AZ, UK.

*Author to whom correspondence should be addressed

r.court@imperial.ac.uk; tel. +44(0)20 75945812.

Abstract. Ablation of micrometeoroids during atmospheric entry yields volatile gases such as water, carbon dioxide and sulfur dioxide, capable of altering atmospheric chemistry and hence the climate and habitability of the planetary surface. While laboratory experiments have revealed the yields of these gases during laboratory simulations of ablation, the reactions responsible for the generation of these gases have remained unclear, with a typical assumption being that species simply undergo thermal decomposition without engaging in more complex chemistry. Here, pyrolysis-Fourier transform infrared spectroscopy reveals that mixtures of meteorite-relevant materials undergo secondary reactions during simulated ablation, with organic matter capable of taking part in carbothermic reduction of iron oxides and sulfates, resulting in yields of volatile gases that differ from those predicted by simple thermal decomposition. Sulfates are most susceptible to carbothermic reduction, producing greater yields of sulfur dioxide and carbon dioxide at lower temperatures than would be expected from simple thermal decomposition, even when mixed with meteoritically relevant abundances of low-reactivity Type IV kerogen. Iron oxides were less susceptible, with elevated yields of water, carbon dioxide and carbon monoxide only occurring when mixed with high abundances of more reactive Type III kerogen. We use these insights to reinterpret previous ablation simulation experiments and to predict the reactions capable of occurring during ablation of carbonaceous micrometeoroids in atmospheres of different compositions. 


\section{Introduction}

\subsection{Production of volatiles from micrometeoroids during ablation}

The terrestrial planets receive an annual flux of micrometeoroids, measuring in the thousands to tens of thousands of tonnes for Earth (Cremonese et al., 2012; Love and Brownlee, 1993). These micrometeoroids experience intense heating and ablation during atmospheric entry that degrades their mineral and organic phases, yielding volatiles gases such as water, carbon dioxide and sulfur dioxide (Court and Sephton, 2014; Greshake et al., 1998; Nozaki et al., 2006; Toppani et al., 2001). This process has drawn considerable attention, as it has the potential to alter atmospheric chemistry and hence climate and the habitability of the planetary surface beneath. While the rate of infall at the present day is far too low to significantly alter atmospheric chemistry, the intense infall associated with the Late Heavy Bombardment (LHB) around four billion years ago was capable of injecting much larger masses of volatiles into the atmospheres of the terrestrial planets, with the ability to contribute to the maintenance of habitable conditions on early Mars (e.g., Court and Sephton, 2014).

While experiments have revealed the yields of volatiles during simulated ablation, less attention has been paid to the chemistry responsible. For example, volatile yields have been inferred via consideration of simple thermal decomposition reactions of mineral and organic species, such as the dehydration of serpentine to anhydrous silicates or the decomposition of calcium carbonate to calcium oxide and carbon dioxide (e.g., Nozaki et al., 2006). However, it is well known that pyrolysis of terrestrial rocks can induce reactions between minerals and the gaseous products of pyrolysis, which can greatly influence the nature of the volatiles produced (e.g., Espitalié et al., 1984; Horsfield and Douglas, 1980). Comparable processes should be expected to occur during the heat of atmospheric entry, meaning that predictions of the yields of volatiles produced during simulated ablation of micrometeoroid analogues need to account for species produced not only via thermal decomposition of constituent materials, hereafter termed "primary" reactions, but also those produced via reactions between the constituent materials, the products of pyrolysis and the local atmosphere, hereafter termed "secondary" reactions.

This is supported by evidence from recent simulated ablation experiments. Yields of carbon dioxide and sulfur dioxide from carbonaceous chondrites pyrolyzed in oxygen-free conditions at certain temperatures cannot be explained by simple thermal decomposition, as sufficient oxygen is not available (Court and Sephton, 2014). Further evidence comes from the spinel rims of micrometeorites recovered from the Antarctic ice, interpreted as the products of reactions between iron-sulfur liquids and atmospheric oxygen (Genge, 2006). Laboratory simulation of ablation has demonstrated that the development of these rims and the abundance of spinel is reduced when the oxygen fugacity is lower (Toppani and Libourel, 2003; Toppani et al., 2001), implying their production via reactions with atmospheric oxygen. These lines of evidence indicate that the products of micrometeoroid ablation are influenced by reactions involving not only the constituents of the micrometeoroid but also atmospheric oxygen. This is particularly significant in the context of Mars or the LHB, as enhanced oxidation resulting from ablation in a modern Earth atmosphere would not be relevant for studies of ablation in the carbon dioxide atmosphere of Mars, or in the low-oxygen atmosphere of Earth prior to oxygenation around $2.4 \mathrm{Ga}$. Hence, predictions of volatile yields from ablating micrometeoroids at times of intense infall must not be made solely on the basis of the decomposition temperatures of constituent materials. It is necessary to also understand the secondary reactions that might occur between micrometeoroid components, their decomposition products and the local atmosphere.

\subsection{Micrometeorites: mineralogy and response to heating}


Most micrometeorites are related to carbonaceous chondrites, particularly those of the $\mathrm{Cl}, \mathrm{CR}$ and $\mathrm{CM}$ groups. They contain hydrated phyllosilicates such as serpentine prior to alteration during atmospheric entry, or produced subsequently upon exposure to terrestrial environments (Imae et al., 2013; Kurat et al., 1994; Taylor et al., 2012). These observations appear to be representative of the micrometeoroid flux over geological time, as implied by the existence of a meteoritic component in the lunar maria soil that resembles CM chondritic material (Wasson et al., 1975) and the presence of carbonaceous microxenoliths, fossil micrometeorites, in meteorites (e.g., Briani et al., 2011). The difficulty of acquiring sufficient masses of pristine micrometeoritic material, and the similarity of carbonaceous chondrites to carbonaceous micrometeoroids, has led to the common use of carbonaceous meteorites such as Orgueil ( $\mathrm{Cl} 1)$ and Murchison (CM2) as proxies to micrometeoroids in experimental work (Court and Sephton, 2009b, 2011, 2014; Füri et al., 2013; Greshake et al., 1998; Nozaki et al., 2006; Toppani et al., 2001).

Simulated ablation of carbonaceous meteorites can reveal the response of these complex mixtures of mineral and organic materials to heating. Water is generated by the loss of sorbed atmospheric water, by the dehydration of hydrated species such as sulfates and, at higher temperatures, by the decomposition of hydrated silicates such as serpentine and saponite (Court and Sephton, 2014). Carbon dioxide is produced by organic matter and carbonates, but stoichiometry has indicated that decomposition of carbonates alone is unable to produce the observed carbon dioxide yields, indicating that secondary oxidation of the insoluble organic matter (IOM) was required (Court and Sephton, 2014). Sulfur dioxide can be produced by elemental and organic sulfur, sulfides and sulfates. However, neither elemental sulfur nor sulfides can generate sulfur dioxide via primary thermal decomposition, as they lack the necessary oxygen. Instead, an external source of oxygen is required (Court and Sephton, 2014). Sulfates are capable of releasing sulfur dioxide via thermal decomposition, but thermal decomposition of gypsum and epsomite, known to exist in carbonaceous meteorites, requires temperatures around $1000{ }^{\circ} \mathrm{C}$, apparently precluding sulfates from being the source of the sulfur dioxide released at lower temperatures.

However, these considerations neglect secondary reactions. In particular, carbothermic reactions, involving the reduction of an oxidized compound by carbon, can result in the evolution of volatiles at significantly lower temperatures. For example, carbon can reduce sulfates to sulfides, while iron oxides, which occur in carbonaceous meteorites as magnetite, are also susceptible to reduction in this fashion, as demonstrated by the industrial process of smelting around $1200{ }^{\circ} \mathrm{C}$. Carbothermic chemistry of this kind can be described by the following reactions (e.g., West and Sutton, 1953; Zheng et al., 2013), where $\mathrm{M}$ is a metal cation such as $\mathrm{Ca}$ or $\mathrm{Mg}$ :

$\mathrm{MSO}_{4}+2 \mathrm{C} \rightarrow \mathrm{MS}+2 \mathrm{CO}_{2}$

$\mathrm{Fe}_{2} \mathrm{O}_{3}+3 \mathrm{C} \rightarrow 4 \mathrm{Fe}+3 \mathrm{CO}_{2}$

\subsection{Investigating secondary reactions during simulated ablation}

Here, we have experimentally simulated the ablation of mixtures of micrometeorite-relevant materials in order to identify and quantify the effects of secondary reactions between mineral and organic components. Pyrolysis of individual materials under an inert atmosphere of helium allows the yields of volatiles produced via thermal decomposition to be established. These yields can be used to project the yields of volatiles expected to occur via thermal decomposition during pyrolysis of mixtures of these materials. Comparison of these projected yields with those actually measured upon pyrolysis of the mixtures allows the volatiles produced by primary thermal decomposition to be distinguished from those produced by secondary reactions. We discuss the reactions responsible 
for the observed variations in volatile yields, and consider their implications for micrometeoroidal infall, in the context of the modern and ancient martian and terrestrial atmospheres.

\section{Materials and methods}

\subsection{Selection of materials}

\subsubsection{Meteorite mineralogy}

The more aqueously altered $\mathrm{C} 1$ chondrites such as Orgueil $(\mathrm{Cl} 1)$ are generally enriched in organic matter, carbonates, sulfates and hydrated phyllosilicates. Organic matter occurs at levels of a few wt.\%, split between soluble species and IOM (e.g., Sephton, 2002). Carbonates are dominated by dolomite in $\mathrm{Cl}$ chondrites (e.g., Fredriksson and Kerridge, 1988), while the CM chondrites contain some calcite (Howard et al., 2009, 2011; Zolensky et al., 1997), along with solid solutions of siderite and magnesite. Sulfates are most abundant in $\mathrm{Cl}$ chondrites, reaching up to 15 wt.\% abundance, commonly as gypsum $\mathrm{CaSO}_{4} \cdot 2 \mathrm{H}_{2} \mathrm{O}$, Ni-blödite $(\mathrm{Na}, \mathrm{Mg}, \mathrm{Ni})\left(\mathrm{SO}_{4}\right)_{2} \cdot 2 \mathrm{H}_{2} \mathrm{O}$ and epsomite $\mathrm{MgSO}_{4} \cdot 7 \mathrm{H}_{2} \mathrm{O}$ (Bullock et al., 2005; Burgess et al., 1991; Fredriksson and Kerridge, 1988; Gao and Thiemens, 1993; Gounelle and Zolensky, 2001). Serpentine is the most common hydrated phyllosilicate in CM chondrites, with abundances of up to 70 wt.\% (Bland et al., 2004), typically with a higher Mg/Fe ratio in more aqueously altered samples (Howard et al., 2009; Lauretta et al., 2000; Tomeoka et al., 1989). In $\mathrm{Cl}$ chondrites, pervasive aqueous alteration has yielded saponite $(\mathrm{Mg}, \mathrm{Fe})_{3} \mathrm{Si}_{4} \mathrm{O}_{10}(\mathrm{OH})_{2} \cdot 4 \mathrm{H}_{2} \mathrm{O}$, intergrown with serpentine and ferrihydrite (e.g., Bland et al., 2004). Anhydrous silicates are generally more common in the less aqueously altered chondrites, with the dominant anhydrous silicate in $\mathrm{CM}$ chondrites being olivine, occurring at 11-17 wt.\%; pyroxene is less abundant, not exceeding 10 wt.\% (Howard et al., 2009, 2011). Sulfide phases include troilite, pyrrhotite, pentlandite and tochilinite (Mackinnon and Zolensky, 1984). Troilite and pyrrhotite are most abundant in $\mathrm{Cl}$ chondrites while pentlandite is more abundant in the $\mathrm{CM}$ chondrites (Bland et al., 2004), with abundances of a few wt.\% being typical (Howard et al., 2009; Zolensky et al., 1993). The degree of iron oxidation is generally greater in the $\mathrm{Cl}$ chondrites, relative to the $\mathrm{CMs}$ (Brearley and Jones, 1998). Magnetite is common, occurring around $10 \mathrm{wt} . \%$ in Orgueil (CI1) but figures of 1-2 wt.\% are more typical for the less aqueously altered CM chondrites (Bland et al., 2004; Howard et al., 2009, 2011; Hyman and Rowe, 1983).

\subsubsection{Materials selected}

A variety of minerals has been selected based on the summary of $\mathrm{Cl} \& \mathrm{CM}$ chondrite mineralogy above. Three iron species have been selected, given their potential to engage in carbothermic reactions: magnetite $\mathrm{Fe}_{3} \mathrm{O}_{4}$ (Sigma-Aldrich, 95\% purity), goethite $\mathrm{FeOOH}$ (Sigma-Aldrich) and a hydrated iron (III) oxide $\mathrm{Fe}_{2} \mathrm{O}_{3} \cdot 2 \mathrm{H}_{2} \mathrm{O}$ (Prolabo). Three sulfates have also been selected: calcium sulfate dihydrate $\mathrm{CaSO}_{4} \cdot 2 \mathrm{H}_{2} \mathrm{O}$ ( $\mathrm{BDH}$ Chemicals, 99\%), anhydrous sodium sulfate $\mathrm{NaSO}_{4}$ (BDH Chemicals, 99\%) and magnesium sulfate heptahydrate $\mathrm{MgSO}_{4} \cdot 7 \mathrm{H}_{2} \mathrm{O}$ (BDH Chemicals, 99.5\%). Two carbonates were used, calcium carbonate $\mathrm{CaCO}_{3}$ (Sigma-Aldrich, 99\%) and magnesium carbonate basic heavy $(\mathrm{BH})$, approximating dypingite $\left(\mathrm{MgCO}_{3}\right)_{4} \mathrm{Mg}(\mathrm{OH})_{2} \cdot 5 \mathrm{H}_{2} \mathrm{O}$ (Botha and Strydom, 2001). Three additional materials were tested: iron (II) sulfide FeS (Sigma-Aldrich, technical grade), partially serpentinized peridotite from The Lizard, UK (henceforth described as serpentinite) and crushed natural olivine, obtained from Mark Sephton of Imperial College London. Meteoritic iron-nickel was not selected because of its status as a minor phase in unmelted micrometeorites (Genge et al., 2008). Study of Antarctic micrometeorites shows that they resemble matrix material in $\mathrm{Cl}, \mathrm{CM}$ and CR chondrites (Genge et al., 1997); while metal is present in CR chondrites, around 7 vol.\%, it is generally present in chondrules rather the matrix (Weisberg et al., 1993). All samples were ground down to a fine powder using an agate pestle and mortar, cleaned before and after use with reverse 
osmosis water and methanol. The grain sizes of the powdered samples were measured at 1-10 $\mu \mathrm{m}$, with both means and standard deviations of the grain diameters being around $5 \mu \mathrm{m}$.

In addition, an analogue to the IOM in carbonaceous meteorites was required. The IOM is described as an organic heteropolymer consisting of condensed aromatic cores connected by aliphatic and ether linkages with various functional groups attached (Cronin et al., 1987; Hayatsu et al., 1977; Sephton, 2002). Complex organic matter in sedimentary rocks, known as kerogen, shares structural similarities with meteorite IOM as a complex organic heteropolymer and has merit as an analogue. However, various types of kerogen are available, representing different environments of formation and alteration. Type I kerogen is typically derived from algae and found in lacustrine sediments, while Type II kerogen is generally derived from planktonic marine organisms. These kerogens typically yield abundant biogenic long-chain $n$-alkanes upon thermal decomposition. However, biogenic $n$-alkanes are not found in meteorites and hence Type I and Type II kerogen are poor analogues to meteoritic organic matter (Matthewman et al., 2013). Type III kerogen is commonly derived from terrestrial land plants and materials such as lignin, a complex heteropolymer of aromatic alcohols. This makes Type III kerogens a better choice as an analogue, relative to Type II kerogens (Ehrenfreund et al., 1991; Hayatsu et al., 1977; Hayatsu et al., 1983; Murae, 1995, 1997; Quirico et al., 2009; Quirico et al., 2003). However, the biogenic origin of Type III kerogens and their abundant phenol species makes them imperfect analogues to meteoritic organic matter (Matthewman et al., 2013). Type IV kerogens consist of organic material, typically terrestrial rather than marine in origin, that has been heavily reworked. Like meteorite IOM, it has very little potential to produce hydrocarbons upon thermal processing and is dominated by aromatic hydrocarbons. The reworking that produces Type IV kerogen typically eliminates much of the biogenic nature of the organic matter, removing or altering aliphatic hydrocarbons and other species characteristic of biology (Matthewman et al., 2013).

Studies of kerogens have revealed their suitability to act as analogues to meteoritic organic matter, revealing that Type IV kerogen in samples of the Great Dirt Bed (GDB) paleosol of the Purbeck Limestone of southern England, collected from the Fossil Forest near Lulworth Cove, Dorset, was the best analogue out of those tested (Matthewman et al., 2013). A difficulty, however, is that the GDB paleosol is not pure kerogen, but occurs mixed with calcium carbonate, silica and clay, as identified by X-ray diffraction (XRD) (Matthewman et al., 2012; Matthewman et al., 2013), forming a black carbonaceous marl (Francis, 1983). Total organic carbon analysis of two samples of GDB from the Fossil Forest yielded a mean figure of $3.47 \mathrm{wt} . \%$; analysis of GDB samples from Portland revealed somewhat lower abundances, of 0.99 wt.\%, 1.90 wt.\% and 2.43 wt.\% (Matthewman et al., 2012). Textural analysis by sieving of a sample of GDB from the Perryfield Quarry in Portland revealed a composition including $50.5 \%$ calcium carbonate and $1.71 \%$ organic carbon (Francis, 1986). Two organic materials have been noted in the GDB; one being a disseminated refractory inertinite and the other being fusain, fossil charcoal interpreted as having been produced in a wildfire (Matthewman et al., 2012; Matthewman et al., 2013). Hence, the volatile yields from Type IV kerogen and its GDB host may still be affected by secondary reactions between the kerogen and minerals. In contrast, Type III kerogens commonly occur as coals, often possessing very low abundances of mineral phases, minimizing this problem. In addition, the greater volatility and reactivity of Type III kerogen, relative to Type IV, is expected to enhance the secondary reactions that are the subject of this investigation. Hence, we have used both Type III and Type IV kerogens as analogues to meteoritic organic matter. The Type III kerogen occurs as a medium-grade, mediumvolatile bituminous coal, similar to the coals studied by Matthewman et al. (2013), while the Type IV kerogen is present in samples of Purbeck Limestone GDB, along with the aforementioned calcium carbonate, silica and clay. Both the coal and the GDB samples were homogenized by crushing using an agate pestle and mortar, both previously cleaned using reverse osmosis water and methanol. 


\subsection{Quantitative pyrolysis-FTIR}

The technique of quantitative pyrolysis-Fourier transform infrared spectroscopy (FTIR) has been employed in several previous investigations (Court and Sephton, 2009a, b, c, 2011, 2014). Ablation is simulated using analytical pyrolysis, and the volatile products of the simulated ablation are identified using FTIR spectroscopy and quantified via reference to calibration curves. Previous pyrolysis-FTIR work has been restricted to a rather simple simulation of ablation, typically employing $15 \mathrm{~s}$ of heating at $1000{ }^{\circ} \mathrm{C}$ (Court and Sephton, 2011, 2014). However, modelling suggests that a micrometeoroid of typical size entering at $45^{\circ}$ at a typical asteroidal velocity of $12 \mathrm{~km} \mathrm{~s}^{-1}$ experiences a rapid increase in temperature to around $1400{ }^{\circ} \mathrm{C}$, followed by rapid cooling (Love and Brownlee, 1991). While small micrometeoroids entering at low angles experience less heating, $99 \%$ of micrometeoroids are expected to be heated to $600{ }^{\circ} \mathrm{C}$ or above (Flynn et al., 2004). Inspection of micrometeorites recovered from Antarctica is generally supportive of this peak temperature, although adding the caveat that temperatures in micrometeorite cores can be much lower, with the gradient between an igneous rim ablating at around $1350{ }^{\circ} \mathrm{C}$ and a cooler micrometeoroid core being supported by endothermic pyrolysis of IOM and the dehydration of silicates (Flynn, 1995; Genge, 2006; Maurette, 1998; Szydlik and Flynn, 1992; Toppani et al., 2001). In light of these considerations, we have selected a temperature profile involving heating at $250{ }^{\circ} \mathrm{C} \mathrm{s}^{-1}$ to a peak temperature of $1300{ }^{\circ} \mathrm{C}$ (the maximum possible using the instrument), holding at $1300{ }^{\circ} \mathrm{C}$ for five seconds, followed by rapid cooling. Preliminary testing of heating profiles had suggested that the yield of volatiles was not strongly dependent on the duration of peak heating, with samples of serpentinite held at $1300^{\circ} \mathrm{C}$ for 2,5 or 8 seconds all giving similar yields of water.

Pyrolysis is performed in a Chemical Data Systems (CDS) Analytical Brill Cell ${ }^{\mathrm{Tm}}$, held at $250{ }^{\circ} \mathrm{C}$ under an atmosphere of helium. The cell temperature of $250{ }^{\circ} \mathrm{C}$ is designed to hinder condensation of volatiles. The inert atmosphere of helium was necessary to exclude atmospheric oxygen, enabling the products of secondary oxidation reactions to be identified. The volatile products of pyrolysis emitted by the sample disperse throughout the Brill Cell, where they are illuminated by the infrared beam, which enters the Brill Cell via zinc selenide windows. Yields of water, carbon dioxide, carbon monoxide, methane and sulfur dioxide were quantified using calibration curves (Court and Sephton, 2009a, b, c, 2011, 2014). These were produced via the direct injection of known volumes of laboratory standard gases, purchased from BOC, at atmospheric pressure through a septum into the Brill Cell using a gas syringe, with the exception of the curve for water, which was produced by the vaporization of known masses of reverse osmosis water.

FTIR spectra were acquired using a Thermo-Nicolet 5700 FTIR spectrometer. FTIR spectra were acquired at a resolution of 4 wavenumbers, a data spacing of $1.928 \mathrm{~cm}^{-1}$, with the final spectrum being produced by the addition of 32 individual spectra. The FTIR spectra of these gases are shown in Fig. 1. Water was quantified using the area of the $3853 \mathrm{~cm}^{-1}$ band; carbon dioxide was quantified using the area of the prominent doublet centered around $2350 \mathrm{~cm}^{-1}$; carbon monoxide was quantified using the height of the broad band centered around $2180 \mathrm{~cm}^{-1}$; methane was quantified using the area of the sharp band at $3015 \mathrm{~cm}^{-1}$ and sulfur dioxide was quantified using the height of the doublet around $1375 \mathrm{~cm}^{-1}$, after the contribution of water to the absorbance in this area had been manually removed (Court and Sephton, 2011). The use of the area of the $2350 \mathrm{~cm}^{-1}$ doublet area to quantify carbon dioxide marks a departure from previous use (e.g., Court and Sephton, 2014). This reflects the presence of excessive noise and variability in measurements of the $670 \mathrm{~cm}^{-1}$ band area, resulting in poor precision and reproducibility, suspected to be related to the high temperatures of pyrolysis employed. Hence, the area of the double band around $2350 \mathrm{~cm}^{-1}$ was used instead. The calibration curves used to quantify the measured infrared band absorbances are detailed in Fig. 2. 


\subsection{Detection of secondary oxidation reactions}

The objective of this investigation was to simulate the ablation of micrometeoroids, to identify secondary reactions of interest and to quantify the yields of volatiles produced by those reactions. It was therefore necessary to recognize and separate the products of simple thermal decomposition of an individual material from the products of reactions between components of a mixture of materials during pyrolysis. This was achieved by comparison of the yields of volatiles from two separate sets of experiments. The first set involved the pyrolysis of pure materials, such as a sample of calcium sulfate dihydrate only, allowing the yields of volatiles produced by thermal decomposition of each material to be determined. Subsequently, further samples were produced by mixing near-equal masses of two components, such as calcium sulfate dihydrate and Type III kerogen. The yields of volatiles produced by thermal decomposition of these mixtures were estimated using the yields identified for each component in the first set of experiments - these are known as the projected yields. For example, if thermal decomposition of individual samples of Type III kerogen and magnetite were to produce yields of carbon dioxide of $1.0 \mathrm{wt} . \%$ and $0.2 \mathrm{wt} . \%$, respectively, then the projected yield from the thermal decomposition of a mixed sample comprising equal masses of Type III kerogen and magnetite would be $0.6 \mathrm{wt} . \%$, halfway between $1.0 \mathrm{wt} . \%$ and $0.2 \mathrm{wt} . \%$. Hence, deviations of the measured yields of volatiles away from the projected yields would indicate the existence of additional secondary reactions between mixtures components.

\section{Results}

Three sets of experiments were performed. Firstly, one-component samples were subjected to pyrolysis, to determine their volatile production upon thermal decomposition without interference from secondary reactions. Secondly, mixtures of a mineral and the Type III kerogen were pyrolysed, followed by a further set of experiments involving pyrolysis of a mineral mixed with Type IV kerogen and its GDB host. In all cases, three aliquots of each sample were analyzed to enable means and standard deviations to be calculated.

\subsection{One-component experiments}

The yields of volatiles from the pyrolysis of pure samples are summarized in Table 1. Pyrolysis of Type III kerogen produced a 6.6 wt.\% yield of water and small amounts of carbon dioxide, carbon monoxide, methane and sulfur dioxide, with yields of each not exceeding $3.0 \mathrm{wt} . \%$. In contrast, pyrolysis of the Type IV kerogen and its GDB host produced no detectable carbon monoxide, methane and sulfur dioxide, but a yield of water of $7.9 \mathrm{wt} . \%$ and a very high, $31.5 \mathrm{wt} . \%$ yield of carbon dioxide.

The iron oxides and goethite produced water and carbon dioxide upon heating, with the other gases not being detected. Iron (III) oxide dihydrate produced the greatest yield of water, $14.0 \mathrm{wt} . \%$, while goethite produced $8.7 \mathrm{wt} . \%$ and magnetite just $2.9 \mathrm{wt} . \%$. Yields of carbon dioxide from these species were very low, less than $0.3 \mathrm{wt} . \%$, with the exception of a $3.4 \mathrm{wt} . \%$ yield from iron (III) oxide dihydrate. The samples of olivine and iron (II) sulfide produced water and carbon dioxide only, with the highest yield being 1.5 wt.\% water from the olivine sample. Serpentinite produced a considerable yield of water, quantified at $13.9 \mathrm{wt.} \%$, along with a low, $0.2 \mathrm{wt} . \%$, yield of carbon dioxide. The three sulfate species showed contrasting responses to pyrolysis. Calcium sulfate dihydrate produced $20.6 \mathrm{wt} . \%$ water and a small amount of carbon dioxide, while magnesium sulfate heptahydrate produced a small yield of sulfur dioxide, $1.6 \mathrm{wt} . \%$, in addition to a $45.8 \mathrm{wt} . \%$ yield of water and traces of carbon dioxide. The anhydrous sodium sulfate produced a little water (0.6 wt.\%), along with traces of carbon dioxide and sulfur dioxide, $0.1 \mathrm{wt} . \%$ and $0.2 \mathrm{wt} . \%$, respectively. Pyrolysis of both calcium carbonate and magnesium carbonate $\mathrm{BH}$ produced abundant 
carbon dioxide, with yields around $25 \mathrm{wt} . \%$. In addition, pyrolysis of magnesium carbonate $\mathrm{BH}$ produced considerable water, with a yield of $20.6 \mathrm{wt} . \%$, while calcium carbonate evolved just 0.4 wt.\% water. Neither carbonate produced detectable carbon monoxide, methane or sulfur dioxide.

\subsection{Two-component mixtures}

Table 2 lists the yields of volatiles produced upon pyrolysis of two-component mixtures. Each mixture comprised kerogen mixed with one mineral phase, in approximately equal quantities. The yields of volatiles in Table 2 reflect the thermal decomposition of the two components, along with the products of any secondary reactions between those components and their products of pyrolysis. All of the mixtures listed in Table 2 produced water, carbon dioxide, carbon monoxide and methane, but sulfur dioxide was absent from certain combinations.

The yields of gases tend to vary as a function of the yields of the gases from the individual components as listed in Table 1, but strong deviations away from this behavior are also apparent. For example, the yields of gases from pyrolysis of mixtures of Type III kerogen and olivine, serpentinite and iron (II) sulfide appear broadly consistent with the yields of gases from these components when pyrolysed separately (Table 1), when normalized to account for the different masses of each phase present. However, the yields of gases from pyrolysis of the mixtures of Type III kerogen and the iron oxides or goethite do not follow this pattern. These mixtures produced high yields of carbon monoxide, around the 5-8 wt.\% mark (Table 2), higher than those produced by either Type III kerogen or the mineral species when pyrolysed individually (Table 1). This excessive production is also seen for water and carbon dioxide; for both of these gases, the yields from mixtures of Type III kerogen and the iron oxides/goethite are greater than the yields of these gases when the mixture components are pyrolysed separately (Table 1). Similar behavior is also seen for the yields of sulfur dioxide, carbon dioxide and carbon monoxide from pyrolysis of mixtures of Type III kerogen and the sulfates. For example, pyrolysis of magnesium sulfate heptahydrate and Type III kerogen produced $5.3 \mathrm{wt} . \%$ sulfur dioxide (Table 2), while pyrolysis of these components individually yielded just $1.6 \mathrm{wt} . \%$ and $0.3 \mathrm{wt} . \%$ sulfur dioxide, respectively (Table 1 ).

In comparison with the Type III kerogen, pyrolysis of mixtures of Type IV kerogen and its GDB host and the mineral species yielded less diverse mixtures of gases. Carbon monoxide and methane are entirely absent, regardless of the mixture composition, while sulfur dioxide is produced only by mixtures including a sulfate or iron (II) sulfide. Yields of carbon dioxide are consistently higher than those seen for the corresponding mixtures involving Type III kerogen, ranging from $17.4 \mathrm{wt}$.\% for the mixture involving goethite to $43.1 \mathrm{wt} . \%$ for the mixture involving magnesium carbonate $\mathrm{BH}$, while mixtures of Type III kerogen and goethite and magnesium carbonate $\mathrm{BH}$ yielded just $2.7 \mathrm{wt} . \%$ and 20.3 wt.\% carbon dioxide, respectively. Yields of water, in contrast, vary with a pattern that generally resembles the pattern of the yields of water from mixtures of Type III kerogen and the mineral species. For example, for both kerogen types, the highest yield of water was produced by mixtures involving magnesium sulfate heptahydrate, while the lowest was produced by mixtures including iron (II) sulfide.

\subsection{Comparison of projected and observed volatile yields for two-component mixtures}

Table 1 lists the wt.\% volatile yields produced upon pyrolysis of the single-component samples. This data can be used to project volatile yields from mixtures of these components, assuming that pyrolysis induces the same thermal decomposition reactions in the each component when part of a mixture as it did when pyrolysed alone. For example, a mixture of Type IV kerogen and calcium sulfate dihydrate might be expected to yield no sulfur dioxide upon pyrolysis, given that neither Type IV kerogen nor calcium sulfate dihydrate produced sulfur dioxide when pyrolysed individually (Table 
1). Following this methodology, Fig. 3 shows the projected yields of each volatile from the mixtures listed in Table 2, calculated using the masses of each component and the wt.\% yields of volatiles from those components as listed in Table 1. Also marked in Fig. 3 are the observed yields from pyrolysis of the two-component mixtures (Table 2). Deviation of the observed yields of gases away from the projected yields implies the existence of additional reactions, capable of releasing or destroying the volatile in question, such as secondary carbothermic reactions. The error bars mark one standard deviation, as calculated using the three analyses performed for each mixture.

Numerous examples of deviations away from the projected yields are apparent in Fig. 3. For mixtures involving Type III kerogen and the iron oxides/goethite, excessive yields of water, carbon dioxide and carbon monoxide are apparent in Figs. 3A-C, while Fig. 3D shows that the yield of methane is considerably lower than projected. The sulfates show similar behavior, with excessive yields of sulfur dioxide, water, carbon dioxide and carbon monoxide being apparent in Figs. 3A-C \& E. Notably, however, the observed yields of methane are similar to those projected (Fig. 3D). The mixtures of Type III kerogen and a carbonate also show deviations away from the projected yields, with excessive production of water and carbon monoxide being visible in Figs. 3A \& C, while lower than expected yields of methane are displayed in Fig. 3D. In contrast, however, mixtures involving olivine, serpentinite and iron (II) sulfide show measured yields of volatiles that are similar to those projected.

A simpler picture is given by Figs. 3F-J, displaying the projected and observed yields of volatiles from pyrolysis of Type IV kerogen and its GDB host mixed with a mineral phase. No carbon monoxide or methane was generated by any mixture (Figs. $3 \mathrm{H}-\mathrm{I}$ ). As with the Type III kerogen, the observed yields of gases from pyrolysis of mixtures of Type IV kerogen and its GDB host and olivine, serpentinite and iron (II) sulfide show no significant deviations away from the projected yields, with the exception of somewhat higher yields of carbon dioxide. Notably, the deviations in the yields of gases observed upon pyrolysis of mixtures of Type III kerogen with the iron oxides/goethite are not replicated when Type IV kerogen and its GDB host is used instead; all yields of volatiles are close to those projected. For the sulfates, however, excessive production of sulfur dioxide is observed (Fig. 3J), similar to the mixtures of sulfate and Type III kerogen (Fig. 3E); elevated yields of carbon dioxide are also seen. Mixtures involving the carbonates show observed yields that match those projected, with the exception of the production of carbon dioxide from mixtures of Type IV kerogen and its GDB host and magnesium carbonate $\mathrm{BH}$, where the observed yields is greatly in excess of the projected one (Fig. 3G).

\section{Discussion}

\subsection{Pyrolytic response of species pyrolysed individually}

Table 1 lists the yields of gases produced upon pyrolysis of single components. Pyrolysis of the Type III kerogen produced all of the five gases quantified here, with the highest yield being 6.6 wt.\% water and the lowest being 0.3 wt.\% sulfur dioxide. While coals such as this are not pure kerogen, the abundance of mineral phases is typically low enough for their chemistry to be dominated by the kerogen. Hence, these yields of gases can be understood as representing the pyrolytic decomposition of the kerogen, liberating species both chemically bound and physically occluded within the kerogen heteropolymer, along with thermally desorbing atmospheric species such as water from the sample. The yield of methane of $1.2 \mathrm{wt} . \%$ and the much greater yield of carbon monoxide (2.9 wt.\%), relative to carbon dioxide (1.0 wt.\%) indicate the paucity of oxygen in the helium-filled pyrolysis cell, the reduced nature of the sample and hence its potential to engage in redox chemistry with oxidized species. 
In contrast, pyrolysis of the Type IV kerogen and its GDB host released a much less diverse mixture of gases. No carbon dioxide, methane or sulfur dioxide was detected; instead, only water and carbon dioxide were produced, with yields of $7.9 \mathrm{wt} . \%$ and $31.5 \mathrm{wt} . \%$, respectively. This behavior reflects the lower abundance of less reactive kerogen in the GDB and the presence of abundant minerals, particularly calcium carbonate, as noted in section 2.1.2. The high yield of carbon dioxide mostly represents thermal decomposition of the calcium carbonate, while the water mostly results from decomposition of hydrated clay minerals as detected by XRD (Matthewman et al., 2012; Matthewman et al., 2013) at the high temperatures of pyrolysis, along with the desorption of sorbed atmospheric water. The absence of carbon monoxide and methane in the pyrolysis products suggests that the Type IV kerogen is less reactive than the Type III kerogen, supporting the conclusion of Matthewman et al. (2013) that it was a superior analogue to meteoritic organic matter.

Pyrolysis of every mineral species alone produced water and carbon dioxide only. Evolution of these species can be attributed to a combination of three sources: thermal decomposition of the relevant mineral phase, the evolution of sorbed atmospheric species and atmospheric leakage into the pyrolysis cell during insertion of the sample. The significance of desorption and leakage can be estimated by considering the yields of water and carbon dioxide from anhydrous or carbon-free minerals. For example, pyrolysis of olivine, iron (II) sulfide, sodium sulfate and calcium carbonate is associated with water yields of $1.5 \mathrm{wt} . \%$ or less. Water should not be evolved during heating of these anhydrous species, meaning that these yields represent the evolution of sorbed atmospheric water and leakage into the pyrolysis cell. However, the $1.5 \mathrm{wt}$.\% yield of water from olivine likely reflects a small degree of impurity, such as aqueous alteration of olivine into hydrated clays, as this was a natural rock sample as opposed to the laboratory chemicals used elsewhere. Hence, these figures indicate that the yields of water reported here are accurate to about $1 \mathrm{wt} . \%$.

Similarly, only the carbonates and the kerogen contain carbon, yet all of the samples produced measurable carbon dioxide, typically at 0.1-0.2 wt.\%. This corresponds to microgram masses of carbon dioxide, consistent with the evolution of sorbed atmospheric gas and minor leakage into the cell during insertion of the sample. However, there are two cases of larger yields which cannot be so easily interpreted in these terms. Pyrolysis of magnetite $\left(\mathrm{Fe}_{3} \mathrm{O}_{4}\right)$ and iron (III) oxide dihydrate produced yields of $2.9 \mathrm{wt} . \%$ water and $3.4 \mathrm{wt} . \%$ carbon dioxide, respectively. These cases most likely reflect impurities in the sample. The magnetite is described as $95 \%$ pure; contamination of it with hydrated iron (III) oxides would be capable of producing the observed yield of water. The nature of the contaminant capable of producing the observed $3.4 \mathrm{wt} . \%$ carbon dioxide from the iron (III) oxide dihydrate is less clear, but carbonate or carbon are possibilities.

Comparison of the observed yields of water and carbon dioxide with those predicted from stoichiometry enables an assessment of whether thermal decomposition of the mineral was complete, or whether the degree of hydration proclaimed for the sample was realistic. For example, a yield of water from goethite of $8.7 \mathrm{wt}$ \% was observed, in comparison to a stoichiometric maximum of $10.1 \mathrm{wt} . \%$, indicating that either some goethite survived pyrolysis, or that there was some contamination by anhydrous iron oxides. Elsewhere, the measured yield of water from calcium sulfate dihydrate of $20.6 \mathrm{wt} . \%$ compares well with a stoichiometrically calculated $20.9 \mathrm{wt} . \%$, but the $25.2 \mathrm{wt} . \%$ yield of carbon dioxide from calcium carbonate is greatly below the stoichiometric maximum of $44.0 \mathrm{wt} . \%$. The composition of the magnesium carbonate $\mathrm{BH}$ was noted as possibly being similar to dypingite, $\left(\mathrm{MgCO}_{3}\right)_{4} \mathrm{Mg}(\mathrm{OH})_{2} \cdot 5 \mathrm{H}_{2} \mathrm{O}$ (Botha and Strydom, 2001). Complete thermal decomposition of this mineral would yield 36.4 wt.\% carbon dioxide and 22.3 wt.\% water; the observed yields of $27.3 \mathrm{wt} . \%$ carbon dioxide and $20.6 \mathrm{wt} . \%$ water is consistent with the incomplete decomposition of a hydrated mineral similar to dypingite. 
No mineral produced carbon monoxide or methane upon pyrolysis, and only two produced detectable sulfur dioxide: magnesium sulfate heptahydrate and sodium sulfate. In both cases, the low yields of sulfur dioxide, of $1.6 \mathrm{wt} . \%$ and $0.2 \mathrm{wt} . \%$, relative to stoichiometric maxima of $26.0 \mathrm{wt} . \%$ and $45.1 \mathrm{wt} \%$, respectively, indicate the thermal stability of sulfates and their resistance to decomposition under these pyrolysis conditions.

\subsection{Secondary reactions during pyrolysis of mixed samples}

\subsubsection{Carbothermic reduction of iron oxides and sulfates}

Fig. 3 reveals that the yields of volatiles produced upon pyrolysis of mixtures of kerogen and mineral phases can differ greatly from the projected yields calculated assuming thermal decomposition only. This indicates that additional chemistry is occurring, involving reactions between the organic and mineral phases, and/or between the gaseous products of pyrolysis. This is most clearly apparent for mixtures involving sulfates and iron oxides or goethite. Pyrolysis of iron oxides or goethite, when mixed with Type III kerogen, is associated with elevated yields of water, carbon dioxide, carbon monoxide, and a reduced yield of methane. Similar behavior is apparent for mixtures of kerogen and sulfate, where excessive production of sulfur dioxide, carbon dioxide and carbon monoxide is clearly visible. The similar responses of the iron oxides and goethite reflect their behavior during the initial stages of heating. Goethite decomposes to iron (III) oxide and water around $200-300{ }^{\circ} \mathrm{C}$ (Naono et al., 1987; Song et al., 2014), while magnetite $\mathrm{Fe}_{3} \mathrm{O}_{4}$ is an intermediate step in the reduction of $\mathrm{Fe}_{2} \mathrm{O}_{3}$ (e.g., Shimokawabe et al., 1979), resulting in similar behavior from all three species.

Section 1.2 proposes two candidate reactions [1] and [2] for carbothermic reduction of iron oxide or sulfates, both yielding carbon dioxide as the gaseous product. However, Fig. 3 shows deviations in the yields of not only carbon dioxide, but also in other gases, demonstrating that the chemistry occurring is more complex than outlined in reactions [1] and [2]. These anomalies can be partially understood via the appreciation that kerogen is not pure carbon but a complex heteropolymer with variable hydrogen and oxygen contents. Hence, oxidation of kerogen would oxidize not only carbon to carbon dioxide, but also hydrogen to water, resulting in the enhanced yields of water and carbon dioxide observed, while incomplete oxidation would generate carbon monoxide. Furthermore, not only carbon but also methane and carbon dioxide are capable of engaging in carbothermic reduction; indeed, the easier mixing of a gas makes carbon monoxide the dominant reductant during reduction of iron ore in a blast furnace, rather than the coke from which it is derived. Reaction of methane with iron oxides in this fashion can explain the decreased yields of methane observed in Fig. 3D. The situation with carbon monoxide is complicated by its generation via partial combustion of kerogen, resulting in the higher than projected yields apparent in Fig. 3C.

However, the production of sulfur dioxide from mixtures involving sulfates seen in Figs. 3E \& J cannot be explained by reaction [1], where a sulfate is simply reduced to a sulfide. Instead, this reflects the reaction of the sulfides produced by carbothermic reduction with the remaining sulfates to yield a metal oxide and sulfur dioxide around $900-1000{ }^{\circ} \mathrm{C}$ (Kale et al., 1992; Scheidema and Taskinen, 2011; van der Merwe et al., 1999), as illustrated below with calcium in equations [3] \& [4] and with the overall equation [5]:

$\mathrm{CaSO}_{4}+2 \mathrm{C} \rightarrow \mathrm{CaS}+2 \mathrm{CO}_{2}$
$3 \mathrm{CaSO}_{4}+\mathrm{CaS} \rightarrow 4 \mathrm{CaO}+4 \mathrm{SO}_{2}$
$2 \mathrm{CaSO}_{4}+\mathrm{C} \rightarrow 2 \mathrm{CaO}+2 \mathrm{SO}_{2}+\mathrm{CO}_{2}$

Reaction [3] uses carbon as the reductant. Inspection of Fig. 3D indicates that methane is not capable of reducing the sulfates instead, as the observed yields of methane match those projected. 
The situation for carbon monoxide is less clear because of the ability of partial oxidation to generate carbon monoxide, as revealed by the enhanced yields apparent in Fig. 3C.

The efficiency of carbothermic reduction can be evaluated by considering the molar efficiency of conversion of sulfate into sulfur dioxide in these experiments. Each mole of sulfate in Table 1 is capable of generating one mole of sulfur dioxide upon thermal decomposition. Calculation of the moles of sulfur dioxide produced upon pyrolysis of the pure sulfate samples indicates that calcium sulfate dihydrate, magnesium sulfate heptahydrate and sodium sulfate experienced molar decomposition efficiencies of $0.0 \%, 6.3 \%$ and $0.5 \%$, respectively, reflecting their considerable thermal stability under these conditions of pyrolysis. In contrast, the same molar calculations for the mixed samples of sulfate and Type III kerogen yield much higher efficiencies of conversion of sulfate into sulfur dioxide, with values of $8.5 \%, 40.2 \%$ and $12.4 \%$ for calcium sulfate dihydrate, magnesium sulfate heptahydrate and sodium sulfate, respectively. These efficiencies demonstrate that only partial carbothermic reduction occurs, despite the presence of an excess of carbon in the $50 \mathrm{wt} . \%$ Type III kerogen contents in the mixtures, sufficient to fuel complete reduction.

Notably, similar molar calculations for the mixed samples of sulfate, Type IV kerogen and its GDB host yields efficiencies of reduction of sulfate into sulfur dioxide that resemble those of the Type III kerogens, despite the low amounts ( $\leq 3.47$ wt.\%) of organic carbon reported in the GDB (Francis, 1986; Matthewman et al., 2012). The calculated molar reduction efficiencies are $9.7 \%, 30.0 \%$ and $6.5 \%$ for calcium sulfate dihydrate, magnesium sulfate heptahydrate and sodium sulfate, respectively. Calculation of the moles of carbon available in the mixed samples of sulfate and GDB indicates that the number of moles of carbon available for carbothermic reduction was about 5.4 times, 2.5 times and 6.2 times the number of moles of calcium sulfate dihydrate, magnesium sulfate heptahydrate and sodium sulfate, respectively, that were reduced to sulfur dioxide. This demonstrates that the chemistry observed was consistent with the reactions outlined in equations [3-5], and emphasizes the incomplete nature of carbothermic reduction. The excess of carbon is understandable in light of the imperfect, micrometer-scale mixing of the samples.

\subsubsection{Additional gas-phase chemistry}

Given the ability of gaseous methane and carbon monoxide to engage in carbothermic reduction, it is worth considering whether additional gas-phase reactions are contributing to the observed yields of volatiles. Gas-phase reactions that may be relevant under these conditions include the Boudouard reaction [6], the water gas reaction [7], the water gas shift reaction [8] and the steam reforming reaction [9].

Boudouard reaction

Water gas reaction

Water gas shift reaction

Steam reforming reaction

$$
\begin{aligned}
& \mathrm{C}+\mathrm{CO}_{2} \rightleftharpoons 2 \mathrm{CO} \\
& \mathrm{C}+\mathrm{H}_{2} \mathrm{O} \rightleftharpoons \mathrm{CO}+\mathrm{H}_{2} \\
& \mathrm{CO}+\mathrm{H}_{2} \mathrm{O} \rightleftharpoons \mathrm{CO}_{2}+\mathrm{H}_{2} \\
& \mathrm{CH}_{4}+\mathrm{H}_{2} \mathrm{O} \rightleftharpoons \mathrm{CO}+3 \mathrm{H}_{2}
\end{aligned}
$$

The Boudouard reaction is particularly relevant, as its ability to generate carbon monoxide from organic matter is an important part of the carbothermic reduction of iron ore during smelting (e.g., Alizadeh et al., 2009; Kale et al., 1992; L'Vov, 2000). The water gas reaction, typically performed by passing steam through red-hot coke, is also capable of yielding carbon monoxide. The water gas shift reaction yields carbon dioxide and hydrogen from carbon monoxide and water at the high temperatures of pyrolysis, typically with an iron oxide-rich catalyst. The steam reforming reaction is employed in industry at $700-1100{ }^{\circ} \mathrm{C}$ with an iron oxide catalyst, conditions comparable to those experienced during pyrolysis in these experiments. The production of carbon monoxide in reactions such as these would be capable of driving further carbothermic reduction reactions 
However, the absence of carbon monoxide in the pyrolysis products of the Type IV kerogen and its GDB host suggest that the Boudouard reaction and water gas reaction did not occur in these experiments, despite the presence of abundant carbon dioxide (Table 1). The possibility that carbon monoxide was produced yet was wholly converted to carbon dioxide in the water gas shift reaction [8] can be discounted in light of the survival of carbon monoxide in the pyrolysis products of the Type III kerogen (Table 1). Indeed, the high ratio of carbon monoxide (2.9 wt.\%) to carbon dioxide (1.0 wt.\% in the pyrolysis products of the Type III kerogen also indicates that the influence of the water gas shift reaction [8] under these reaction conditions is low or non-existent. Applying this argument to the steam reforming reaction [9] is more equivocal, as the $2.9 \mathrm{wt} . \%$ yield of carbon monoxide from Type III kerogen may derive directly from the kerogen, or indirectly via the steam reforming reaction, given the lower yield of methane of $1.2 \mathrm{wt} . \%$. However, the steam reforming reaction is typically performed industrially at high pressures, in the region of 20 bar. Hence, it seems improbable that it is occurring to any significant extent in these pyrolysis reactions, particularly given the brief residence time of the gases before their expulsion from the hot sample. Therefore, there is no clear evidence of any of the gas phases reactions [6-9] occurring in these experiments.

\subsubsection{Significance of water}

A notable feature of the sulfates and carbonates is their varying water contents, with yields ranging from $<1 \mathrm{wt} . \%$ for sodium sulfate and calcium carbonate to $45.8 \mathrm{wt} . \%$ for magnesium sulfate heptahydrate (Table 1). For the sulfates, no clear relationship between water abundance and volatile yield can be identified. Pyrolysis of the mixture of Type III kerogen and the water-rich magnesium sulfate heptahydrate produced the highest yield of sulfur dioxide among the sulfates, $5.3 \mathrm{wt} . \%$, yet yields of sulfur dioxide correlate poorly with sulfate water content and better with the yield of sulfur dioxide produced upon pyrolysis of sulfate alone (Table 1).

For the carbonates, however, considerable differences in volatile yields are apparent. The hydrated magnesium carbonate $\mathrm{BH}$ is associated with elevated yields of carbon dioxide when mixed with either kerogen type, relative to calcium carbonate. Notably, the $43.1 \mathrm{wt} \%$ yield of carbon dioxide from the mixture of magnesium carbonate $B H$ and GDB exceeds the yields from these two components when pyrolysed individually, and is too great to be derived from oxidation of an organic carbon content in the vicinity of $3.47 \mathrm{wt} . \%$ (Matthewman et al., 2012). Instead, the excess carbon dioxide is most likely derived from the decomposition of calcium carbonate in the GDB sample. However, it is not clear why carbonate decomposition should be enhanced in the mixed samples. It may not reflect a chemical process, but instead result from the easier conduction of heat into the centre of a mixed sample that possesses a lower carbonate content and hence experiences less cooling via endothermic decomposition of carbonate and advection of hot carbon dioxide. This effect may also be responsible for the somewhat elevated yields of carbon dioxide produced by mixtures of GDB and olivine, serpentinite and iron (II) sulphide (Fig. 3G).

\subsection{Implications for volatile generation from ablating micrometeoroids}

\subsubsection{Relevance of kerogen types to micrometeoroids}

The results presented here indicate that both kerogen types can engage in secondary reactions with various common micrometeoritic minerals. For the Type III kerogen, reactions with iron oxides generated additional water, carbon dioxide and carbon monoxide and decreased yields of methane, and reactions with sulfates generated extra carbon dioxide, carbon monoxide and sulfur dioxide, again with methane yields being reduced. For the Type IV kerogen and its GDB host, reactions with 
iron oxides did not occur; instead, only the sulfates reacted, yielding elevated amounts of sulfur dioxide and carbon dioxide.

These differences can be understood as functions of the abundances and reactivity of organic matter. The mixtures of Type III kerogen and a mineral contain about 50 wt.\% organic matter, reflecting the high organic content of the Type III kerogen. In contrast, the $3.47 \%$ organic carbon content of the GDB (Matthewman et al., 2012) decreases to about 1.7 wt.\% upon mixing with the mineral phase, resulting in a much lower concentration of organic matter in the samples that produced the data displayed in Fig. 3F-J. Hence, reaction of the iron oxides and goethite occurred only when large amounts of the more reactive Type III kerogen were present. In contrast, the low abundances of the less reactive Type IV kerogen were still sufficient to drive chemistry with the sulfates. Given this contrasting chemistry, the relevance of the kerogen types to meteoritic materials must therefore be established.

It was noted in Section 2.1.2 that Type III kerogen was inferior to Type IV kerogen as an analogue for meteoritic organic matter because of its biological origin and abundance of phenol species (Matthewman et al., 2013). Here, this inferiority manifests itself via the production upon pyrolysis of yields of carbon monoxide and methane of about $3 \mathrm{wt} . \%$ and $1 \mathrm{wt} . \%$, respectively. In contrast, pyrolysis of samples of carbonaceous chondrites produces yields of these gases on the ppm scale (Butterworth et al., 2004; Court and Sephton, 2009a; Sephton, 2002). Furthermore, the high abundance of organic matter in mixtures containing Type III kerogen, around 50 wt.\%, is unrepresentative of the 2-3 wt. \% organic content of a typical carbonaceous meteorite (e.g., Sephton, 2002), which instead more closely resembles the $<3.5 \mathrm{wt} . \%$ organic content of the GDB (Francis, 1986; Matthewman et al., 2012). While pyrolysis-GC-MS studies indicated that the Type IV kerogen in the GDB made a satisfactory analogue to meteoritic organic matter, it was also noted that the rock matrix of the GDB paleosol was very different to that of the typical carbonaceous chondrite (Matthewman et al., 2013). Meteorites such as Murchison (CM2) and Orgueil (Cl1) are dominated by hydrated phyllosilicates and contain only small amounts of organic matter, sulfides, sulfates and carbonates, typically, $<5$ wt.\% (e.g., Bland et al., 2004). In contrast, the GDB is much more enriched in carbonate (Francis, 1983, 1986; Matthewman et al., 2012; Matthewman et al., 2013). While the carbonate could have been eliminated via acid demineralization, this would have increased the concentration of kerogen in the GDB samples to levels less representative of meteoritic materials.

Hence, although neither the kerogens investigated here can be regarded as ideal analogues, both offer useful information on the reactions expected to occur during ablation of an infalling micrometeoroid. The data from the Type III kerogen can be used to infer the reactions capable of occurring in a micrometeoroid highly enriched in reactive, labile organic matter, while the data from the Type IV kerogen can be used to infer the chemistry occurring in a micrometeoroid possessing a more typical abundance of refractory organic matter.

\subsubsection{Application to carbonaceous meteoroid mineralogy}

Carbonaceous meteorites such as Murchison (CM2) and Orgueil (CI1) contain abundant (up to 70 wt.\%) hydrated phyllosilicates such as serpentine and saponite, along with up to about 15 wt.\% anhydrous silicates such as olivine and pyroxene. Magnetite and sulfates can occur at levels of around 5-10 wt.\%, while species such as sulfides, carbonates and organic matter normally have abundances of $<5$ wt.\% (e.g., Bland et al., 2004). The most abundant minerals in carbonaceous chondrites of those investigated here, serpentine and olivine, show no significant tendency to engage in secondary reactions, nor do the less abundant sulfides. Hence, despite their abundance in carbonaceous chondrites and the intimate intermingling commonly seen in meteoritic materials 
(e.g., Pearson et al., 2002), these minerals are not expected to engage in secondary reactions with organic matter during ablation to any significant degree.

Magnetite is capable of engaging in carbothermic chemistry when mixed with Type III kerogen (Fig. 3); however, these reactions were not observed when Type IV kerogen was used instead. As discussed in Section 4.3.1, this likely reflects the lesser abundance and reduced reactivity of the Type IV kerogen in the GDB sample, relative to the Type III kerogen in the coal. Given that the abundance and chemistry of the kerogen of the GDB more closely resembles meteoritic IOM, relative to the Type III kerogen-containing coal, the data suggest that carbothermic reduction of iron oxides is not an important reaction during atmospheric ablation of carbonaceous micrometeoroids.

Sulfates showed considerable reactivity with both types of kerogen, yielding elevated abundances of both carbon dioxide and sulfur dioxide. Moreover, the magnitudes of the deviations away from the projected yields of volatiles are approximately the same for both kerogen types, regardless of the differences in organic matter abundance and chemistry. This indicates that reactions between sulfates and organic matter, generating excess sulfur dioxide and carbon dioxide, should be expected to occur during micrometeoritic infall. This is particularly relevant given the high resistance of sulfates to thermal decomposition. Table 1 indicates that heating any of the sulfates to $1300{ }^{\circ} \mathrm{C}$, not far from the temperature of peak ablation, is insufficient to produce a yield of sulfur dioxide from samples of pure sulfate of more than $1.6 \mathrm{wt} . \%$. However, Table 2 demonstrates that the presence of a small amount of Type IV kerogen in a sulfate exposed to that temperature results in yields of sulfur dioxide around four times greater than projected, taking the data for all the sulfates together.

Overall, it can be concluded that the elevated production of volatiles via secondary reactions between micrometeoroid components is likely to be restricted to carbothermic reduction of sulfates by organic matter. This behavior is most significant for objects containing abundant sulfates and organic matter, such as $\mathrm{Cl}$ and $\mathrm{CM}$ chondrites, where these species occur at levels of $<15 \mathrm{wt} . \%$ and 23 wt.\%, respectively (Alexander et al., 2007; Baker, 1971; Howard et al., 2011; Pearson et al., 2006; Sephton, 2002). However, it must also be considered whether sufficient IOM is available to reduce the sulfate present, given that one mole of carbon is consumed during the conversion of two moles of sulfate to two moles of sulfur dioxide as per equation [5], and that the carbothermic reduction observed in the mixtures of sulfate and Type IV kerogen involved a molar ratio of carbon to sulfate between 2.5:1 for magnesium sulfate heptahydrate and 6.2:1 for sodium sulfate (section 4.2.1).

Orgueil (CI1) and Murchison (CM2) contain IOM abundances of 2.00 wt.\% (Alexander et al., 2007) and 1.45 wt.\% (Mullie and Reisse, 1987; Sephton, 2002), with the IOM possessing a carbon content of about 78\%, assuming an average composition of IOM of $\mathrm{C}_{100} \mathrm{H}_{48} \mathrm{~N}_{1.8} \mathrm{O}_{12} \mathrm{~S}_{2}$ (Zinner, 1988). Orgueil $(\mathrm{Cl} 1)$ has sulfate abundances reported at 1.5-3.5 wt.\% gypsum, $5.1 \mathrm{wt} . \%$ epsomite and $7.24 \mathrm{wt} . \% \mathrm{Ni}$ blödite (Burgess et al., 1991; Fredriksson and Kerridge, 1988), while Murchison (CM2) possesses sulfate abundances of 1.29 wt.\% gypsum and 6.07 wt.\% epsomite (Burgess et al., 1991). Conversion of these abundances of IOM and sulfates into moles produces molar ratios of carbon to total sulfate of about 1.5 for Orgueil $(\mathrm{Cl} 1)$ and 2.9 for Murchison (CM2). These ratios are comparable to those observed for the mixtures of GDB organic carbon and sulfate and demonstrate that sufficient carbon is available in these chondrites for significant carbothermic reduction of their sulfate budgets.

This demonstrates that yields of sulfur dioxide and carbon dioxide from ablating carbonaceous micrometeoroids based solely on considerations of temperatures of thermal decomposition are likely to be greatly underestimated, and that reaction with atmospheric oxygen is not essential to generate high yields of oxidized gases. The ability of these gases to alter surface climate and habitability via their greenhouse properties, or via the ability of sulfur dioxide to form sunlight- 
scattering sulfate aerosols, makes a proper understanding of the chemistry occurring during ablation essential to fully understand surface conditions on Earth and Mars during the time of the LHB, around the time of the origin of life on Earth. This emphasizes the value of realistic experimental simulations.

\subsubsection{Application to previous simulation experiments}

Stepped pyrolysis was used by Court and Sephton (2014) to simulate the atmospheric ablation of micrometeoroids and to gain insights into the mineralogy of carbonaceous chondrites. It was noted that the yields of sulfur dioxide and, to a lesser extent, carbon dioxide were considerably greater under the stepped pyrolysis regime, relative to single-step pyrolysis experiments performed previously (Court and Sephton, 2011, 2014). This was ascribed to the repeated heating cycles required as part of the stepped pyrolysis regime (Court and Sephton, 2014), despite previous work suggesting that a $100{ }^{\circ} \mathrm{C}$ difference in temperature of heating was more significant than an order of magnitude difference in heating duration (Nozaki et al., 2006). The excess sulfur dioxide was tentatively attributed to the reaction of hot sulfides with water to yield elemental sulfur (Böstrom and Fredriksson, 1966), which would readily oxidize to sulfur dioxide at the temperatures of pyrolysis.

However, this reaction is not capable of explaining the enhanced yields of carbon dioxide upon stepped pyrolysis of Orgueil (Cl1) and Cold Bokkeveld (CM2), relative to bulk pyrolysis, reported by Court and Sephton (2014). Carbothermic reduction of sulfates offers a better solution. Two moles of sulfur dioxide are produced by carbothermic reduction of sulfate for every one mole of carbon dioxide (reaction [5]), a 3:1 mass ratio. This is compatible with the levels of excess production of sulfur dioxide and carbon dioxide noted for Orgueil (Cl1) and Cold Bokkeveld (CM2) in Fig. 3 of Court and Sephton (2014). It is also compatible with the elevated abundances of sulfates in these chondrites. Orgueil has reported values of 1.5-3.5 wt.\% gypsum, $5.1 \mathrm{wt. \%}$ epsomite and 7.24 wt.\% Ni-blödite (Burgess et al., 1991; Fredriksson and Kerridge, 1988), while Cold Bokkeveld possesses 0.8 vol.\% gypsum (Howard et al., 2009, 2011). In contrast, the generally lower abundance of sulfates in ALH 88045, Murchison and Mokoia restricted the potential for carbothermic reduction and hence limited the excess of carbon dioxide produced by stepped pyrolysis, relative to bulk pyrolysis. These data further support the idea that micrometeoroidal sulfate is susceptible to carbothermic reduction and the release of sulfur dioxide and carbon dioxide at temperatures below those of thermal decomposition.

Burgess et al. (1991) used stepped combustion to infer the mineralogy of sulfur-bearing components, based on their temperatures of reaction with oxygen to yield sulfur dioxide, as established by stepped combustion analysis of a mixture of reference materials - sulfur, troilite, gypsum and epsomite. However, the reference mixture lacked the organic matter capable of driving the carbothermic reactions described above. If carbothermic reactions between meteoritic components were occurring during the stepped combustion experiments, then sulfur-bearing components, particularly sulfates, could react at unexpected temperatures, leading to misinterpretations of the nature of the source materials. However, there is good reason to conclude that this is not an issue. The data presented here indicate that sulfides are not susceptible to secondary reactions in this fashion. The oxygen-rich atmosphere used by the stepped combustion experiments would have efficiently oxidized the organic matter required for carbothermic reduction below $600{ }^{\circ} \mathrm{C}$, while carbothermic reactions between sulfates and organic matter are expected to occur above this temperature (Kale et al., 1992; Mu and Perlmutter, 1981; Scheidema and Taskinen, 2011; Strydom et al., 1997; van der Merwe et al., 1999; West and Sutton, 1953; Zheng et al., 2013). 
Greshake et al. (1998) simulated atmospheric entry using samples of Orgueil (CI1) under air at 1 bar. The presence of air means that abundant oxygen was available for combustion of IOM. However, unlike the stepped heating of Burgess et al. (1991), Greshake et al. (1998) employed pulse heating, whereby small $(100 \mu \mathrm{m})$ samples of Orgueil were exposed to a hot furnace. Heating for $20 \mathrm{~s}$ at 800 ${ }^{\circ} \mathrm{C}$ was sufficient to evolve about $30 \%$ of the sulfur content, while $1000{ }^{\circ} \mathrm{C}$ was able to remove about $90 \%$. The loss of sulfur in the $800-1000{ }^{\circ} \mathrm{C}$ window was attributed to sulfates, but it was noted that two of the sulfates common in $\mathrm{Cl}$ chondrites, epsomite and gypsum (Burgess et al., 1991), possessed elevated decomposition temperatures, stated as $1124{ }^{\circ} \mathrm{C}$ and $1193{ }^{\circ} \mathrm{C}$, respectively, and these sulfates were instead assigned to the sulfur produced around $1200{ }^{\circ} \mathrm{C}$ (Greshake et al., 1998; Smykatz-Kloss, 1974). Therefore, the data of Greshake et al. (1998) implies that about six times as much sulfur was released in the $800-1000{ }^{\circ} \mathrm{C}$ region by $\mathrm{Ni}$-blödite as was released at $1100{ }^{\circ} \mathrm{C}$ and above by epsomite and gypsum. This ratio of $\mathrm{Ni}$-blödite to epsomite and gypsum is difficult to reconcile with the $<7.24$ wt.\% Ni-blödite $\left(\mathrm{NiNaMg}\left(\mathrm{SO}_{4}\right)_{2} \cdot 4 \mathrm{H}_{2} \mathrm{O}\right)$, the 3.53 wt.\% gypsum and the 5.07 wt.\% epsomite contents reported by Burgess et al. (1991). The potential for carbothermic reduction of sulfate during these pulse heating experiments offers some insight here. In contrast to the stepped combustion experiments of Burgess et al. (1991), the rapid heating of the sample during the pulse heating experiments of Greshake et al. (1998) means that the sample should be expected to achieve the temperatures required for carbothermic reduction before combustion of the organic matter had occurred, indicating the availability of organic matter for carbothermic reduction capable of causing the efficient loss of sulfate sulfur from the samples of Orgueil in the $800-1000{ }^{\circ} \mathrm{C}$ region, much lower than expected by Greshake et al. (1998).

Reports of the detection of small amounts of methane in the atmosphere of Mars have raised hopes that it may reflect the presence of methanogenic life, although abiological explanations such as meteoritic and cometary infall or serpentinization are generally favored (Atreya et al., 2007; Formisano et al., 2004; Geminale et al., 2008; Krasnopolsky, 2006; Krasnopolsky et al., 2004; Webster et al., 2013; Webster et al., 2015). Court and Sephton (2009a) investigated the potential of carbonaceous micrometeoroids to produce methane during simulated atmospheric ablation, but, finding a yield of methane of just $8 \mathrm{ppm}$, concluded that this mechanism could only account for a tiny fraction of the annual production of methane required on Mars. However, the simulation of ablation employed by Court and Sephton (2009a) involved samples of Murchison (CM2) previously demineralized by hydrochloric and hydrofluoric acid. Demineralization was performed in order to concentrate the sparse (1.45 wt.\% (Chang et al., 1978; Sephton, 2002)) IOM content of Murchison. However, as demonstrated here, the thermal decomposition of meteoritic materials does not proceed in isolation but can involve reactions between the components present. In this case, simulated ablation of mixtures of Type III kerogen and iron oxides, goethite, calcium carbonate or magnesium carbonate $\mathrm{BH}$ is associated with reduced yields of methane, interpreted to represent the carbothermic reduction of mineral phases by methane released by the kerogen. This suggests that ablation of whole-rock Murchison might produce less than the $8 \mathrm{ppm}$ yield of methane inferred from the study of demineralized Murchison, because of the potential for destruction of methane via reactions with the $1.1 \mathrm{wt} . \%$ calcite and $0.4 \mathrm{wt} . \%$ magnetite contents of Murchison (Bland et al., 2004). This further restricts the ability of micrometeoritic infall to inject methane into the atmosphere of Mars and suggests that estimate of $8 \mathrm{~kg}$ of annual methane production by this mechanism (Court and Sephton, 2009a) may be an overestimate.

\subsubsection{The role of atmospheric oxygen}

The influence of atmospheric chemistry on the yields of volatiles from ablating micrometeoroids is not well understood. Simulations of ablation have employed a range of pressures and gas compositions, such as helium at 1 bar (Court and Sephton, 2009a, b, c, 2011, 2014), air at 1 bar (Greshake et al., 1998), air and carbon dioxide-nitrogen mixtures at 1 bar (Toppani and Libourel, 
2003; Toppani et al., 2001) and air at $<10^{-3}$ bar (Nozaki et al., 2006). The uncertainty regarding the appropriate atmospheric composition and pressure to use reflects the uncertainty regarding the processes operating during ablation. For example, peak ablation occurs at an altitude of about 100 $\mathrm{km}$ where atmospheric pressure is around $10^{-5}$ bar, suggesting that ablation could be simulated in an inert atmosphere at 1 bar to reflect the scarcity of reactive species. However, although micrometeorites are expected to be too small to generate bow shocks (Love and Brownlee, 1991), the rapid passage through the atmosphere may be capable of concentrating molecules in the hot ablation rim where they can react with the micrometeoroid. Alternatively, this process may be overwhelmed by the outflow of gases produced by decomposition of minerals in the ablating micrometeoroid, which would imply that the gases available for reaction would reflect the mineralogy of the micrometeoroid.

However, studies of the cosmic spinels formed during ablation via partial melting and crystallization of iron-sulfur eutectic liquids in micrometeorites (Genge, 2006) and in the fusion crusts of meteorites has revealed relationships between temperature, duration of heating and oxygen fugacity (Toppani and Libourel, 2003) that demonstrate that atmospheric oxygen is able to influence the chemistry occurring during ablation. This implies that organic matter can be oxidized by atmospheric oxygen at relatively low temperatures, restricting its ability to participate in carbothermic reduction of oxides and/or sulfates. This would mean that the yield of volatiles from ablating micrometeoroids would be influenced by atmospheric chemistry, with important implications for non-oxygenated atmospheres, such as those of Mars or of the early Earth.

Determination of the influence of atmospheric composition on the yields of volatiles requires dedicated simulations of ablation. However, we can predict the general effects of this behavior on volatile yields. Atmospheric oxygen is able to oxidize organic matter, reducing its ability to take part in carbothermic chemistry and hence lowering yields of sulfur dioxide, yet elevated atmospheric oxygen contents would also favor the direct oxidation of sulfides, and it is not clear which effect would dominate. Similarly, a reduced potential for the production of carbon dioxide via carbothermic reduction of sulfates could be balanced by increased direct oxidation of organic matter by atmospheric oxygen. The carbon dioxide-rich atmospheres of Mars and, to a lesser extent, early Earth offer the possibility of additional chemistry. The absence of significant oxygen would inhibit oxidation of sulfides and organic matter as discussed above, while abundant carbon dioxide would also inhibit carbonate decomposition reactions. A carbon dioxide atmosphere may also promote Boudouard formation of carbon monoxide via reaction of carbon dioxide with hot carbon in the ablating micrometeoroid. Carbon monoxide produced in this fashion could then drive carbothermic reduction of iron oxides and sulfates as seen in Fig. 3, hence increasing yields of sulfur dioxide and carbon dioxide. 


\section{Conclusions}

1. Experimental simulation of atmospheric ablation of micrometeoroids demonstrates the ability of organic matter to react with common meteoritic minerals, resulting in yields of water, carbon dioxide and sulfur dioxide that differ from those projected from considerations of the thermal decomposition temperatures and yields of volatiles from minerals such as carbonates and sulfates.

2. Sulfates are most vulnerable to these secondary reactions, yielding additional carbon dioxide and sulfur dioxide at temperatures lower than their typical temperatures of thermal decomposition when mixed with both of the kerogen analogues to meteoritic organic matter. Iron oxides and carbonates are also susceptible, but the absence of carbothermic reactions in the samples involving the Type IV kerogen-bearing GDB suggests that high concentrations of organic matter, unrepresentative of meteoroidal materials, are required.

3. The GDB, with its $<3.5$ wt.\% abundance of Type IV kerogen, makes a better proxy for a carbonaceous meteoritic than the carbon-rich coal. Carbothermic reduction of sulfates during 1300 ${ }^{\circ} \mathrm{C}$ pyrolysis of mixtures of sulfate and GDB produced yields of sulfur dioxide that were about four times greater than those produced by pyrolysis of sulfates alone. The similarity of the abundances of organic carbon in these mixtures, around $1.7 \mathrm{wt} . \%$, with the 1-2 wt.\% abundances of IOM in the carbonaceous chondrites Orgueil (CI1) and Murchison (CM2), together with the 7-15 wt.\% abundances of sulfate in those meteorites, indicates that sufficient organic matter and sulfate is available in these meteorites to produce significant amounts of additional sulfur dioxide via carbothermic reduction.

4. These results allow reinterpretation of previous ablation simulation experiments. The production of sulfur dioxide at anomalously low temperatures during stepped pyrolysis experiments noted by Court and Sephton (2014) can be understood in terms of carbothermic reduction of sulfates at temperatures lower than those required for production of sulfur dioxide via thermal decomposition in the absence of organic matter. This is capable of explaining the elevated yields of sulfur dioxide from samples of carbonaceous chondrites subjected to stepped pyrolysis, relative to samples subjected to bulk pyrolysis (Court and Sephton, 2014). Similarly, pulse heating experiments on samples of carbonaceous chondrites performed by Greshake et al. (1998) revealed a more efficient loss of sulfur at $1000{ }^{\circ} \mathrm{C}$ than would be expected simply from thermal decomposition of the sulfate minerals present. The destruction of methane in carbothermic reactions observed here cannot offer an explanation for the low yields of methane observed upon simulated ablation of demineralized samples of IOM from the CM2 Murchison chondrite (Court and Sephton, 2009a). Instead, the data suggest that the reported yield of methane of $8 \mathrm{ppm}$ represents an upper limit, likely to be reduced further by the destruction of methane via reaction with minerals during ablation.

5. The ability of meteoritic materials to undergo secondary reactions between components, together with variations in meteoritic spinel chemistry related to oxygen fugacity, demonstrate that the atmospheric composition is capable of influencing yields of volatiles from micrometeoroids during ablation. The oxygen-rich atmosphere of Earth enhances direct oxidation of organic matter during ablation, restricting the amount available to engage in carbothermic reactions with iron oxides and sulfates, yet may also promote the oxidation of mineral phases. An oxygen-poor, carbon dioxide-rich atmosphere such as exists on Mars and Venus, and that existed on the early Earth, may instead promote carbothermic reduction of iron oxides and sulfates, as hot micrometeoritic carbon reacts with atmospheric carbon dioxide via the Boudouard generation to produce carbon monoxide. The uncertainty regarding the implications of this complex scheme of reactions demonstrates the need for a better understanding of the mechanisms of volatile generation during atmospheric ablation of micrometeoroids. 
Acknowledgements. This work was supported by a UK Space Agency Aurora Fellowship and a UROP studentship funded by the Department of Earth Sciences and Engineering, Imperial College London. We would like to thank Mark Sephton for the supply of the olivine samples, and Evelyn Füri and an anonymous reviewer for their very detailed and helpful reviews. 


\section{References}

Alexander C. M. O., Fogel M., Yabuta H., and Cody G. D. 2007. The origin and evolution of chondrites recorded in the elemental and isotopic compositions of their macromolecular organic matter. Geochimica et Cosmochimica Acta 71:4380-4403.

Alizadeh R., Jamshidi E., and Zhang G. 2009. Transformation of methane to synthesis gas over metal oxides without using catalyst. Journal of Natural Gas Chemistry 18:124-130.

Atreya S. K., Mahaffy P. R., and Wong A. S. 2007. Methane and related trace species on Mars: Origin, loss, implications for life, and habitability. Planetary and Space Science 55:358-369.

Baker B. L. 1971. Review of organic matter in the Orgueil meteorite. Space Life Sciences 2:472-497.

Bland P. A., Cressey G., and Menzies O. N. 2004. Modal mineralogy of carbonaceous chondrites by Xray diffraction and Mossbauer spectroscopy. Meteoritics \& Planetary Science 39:3-16.

Böstrom K. and Fredriksson K. 1966. Surface conditions of the Orgueil parent body as indicated by mineral associations. Smithsonican Miscellaneous Collections 151:1-39.

Botha A. and Strydom C. A. 2001. Preparation of a magnesium hydroxy carbonate from magnesium hydroxide. Hydrometallurgy 62:175-183.

Brearley A. J. and Jones R. H. 1998. Chondritic meteorites. In Planetary Materials, edited by Papike J. J. Washington, D.C.: Mineralogical Society of America. pp. 3.1-3.398.

Briani G., Morbidelli A., Gounelle M., and Nesvorny D. 2011. Evidence for an asteroid-comet continuum from simulations of carbonaceous microxenolith dynamical evolution. Meteoritics \& Planetary Science 46:1863-1877.

Bullock E. S., Gounelle M., Lauretta D. S., Grady M. M., and Russell S. S. 2005. Mineralogy and texture of Fe-Ni sulfides in $\mathrm{Cl} 1$ chondrites: Clues to the extent of aqueous alteration on the Cl1 parent body. Geochimica et Cosmochimica Acta 69:2687-2700.

Burgess R., Wright I. P., and Pillinger C. T. 1991. Determination of sulfur-bearing components in C1 and $C 2$ carbonaceous chondrites by stepped combustion. Meteoritics 26:55-64.

Butterworth A. L., Aballain O., Chappellaz J., and Sephton M. A. 2004. Combined element (H and C) stable isotope ratios of methane in carbonaceous chondrites. Monthly Notices of the Royal Astronomical Society 347:807-812.

Chang S., Mack R., and Lennon K. 1978. Carbon chemistry of separated phases of Murchison and Allende meteorites. Lunar and Planetary Science 9:157-159.

Court R. W. and Sephton M. A. 2009a. Investigating the contribution of methane produced by ablating micrometeorites to the atmosphere of Mars. Earth and Planetary Science Letters 288:382-385.

Court R. W. and Sephton M. A. 2009b. Meteorite ablation products and their contribution to the atmospheres of terrestrial planets: An experimental study using pyrolysis-FTIR. Geochimica et Cosmochimica Acta 73:3512-3521.

Court R. W. and Sephton M. A. 2009c. Quantitative flash pyrolysis Fourier transform infrared spectroscopy of organic materials. Analytica Chimica Acta 639:62-66.

Court R. W. and Sephton M. A. 2011. The contribution of sulphur dioxide from ablating micrometeorites to the atmospheres of Earth and Mars. Geochimica et Cosmochimica Acta 75:1704-1717.

Court R. W. and Sephton M. A. 2014. New estimates of the production of volatile gases from ablating carbonaceous micrometeoroids at Earth and Mars during an E-belt-type Late Heavy Bombardment. Geochimica et Cosmochimica Acta 145:175-205.

Cremonese G., Borin P., Martellato E., Marzari F., and Bruno M. 2012. New calibration of the micrometeoroid flux on Earth. Astrophysical Journal Letters 749.

Cronin J. R., Pizzarello S., and Frye J. S. $1987 .{ }^{13} \mathrm{C}$ NMR spectroscopy of the insoluble carbon of carbonaceous chondrites. Geochimica et Cosmochimica Acta 51:299-303.

Ehrenfreund P., Robert F., D'Hendecourt L., and Behar F. 1991. Comparison of interstellar and meteoritic organic matter at 3.4 $\mu \mathrm{m}$. Astronomy and Astrophysics 252:712-717. 
Espitalié J., Senga Makadi K., and Trichet J. 1984. Role of the mineral matrix during kerogen pyrolysis. Organic Geochemistry 6:365-382.

Flynn G. J. 1995. Thermal gradients in interplanetary dust particles: The effect of an endothermic phase transition. Abstracts of the Lunar and Planetary Science Conference 26:405.

Flynn G. J., Keller L. P., Jacobsen C., and Wirick S. 2004. An assessment of the amounts and types of organic matter contributed to the Earth by interplanetary dust. Advances in Space Research 33:57-66.

Formisano V., Atreya S., Encrenaz T., Ignatiev N., and Giuranna M. 2004. Detection of methane in the atmosphere of Mars. Science 306:1758-1761.

Francis J. E. 1983. The dominant conifer of the Jurassic Purbeck Formation, England. Palaeontology 26:277-294.

Francis J. E. 1986. The calcareous paleosols of the basal Purbeck Formation (Upper Jurassic), southern England. In Paleosols: their recognition and interpretation, edited by Wright V. P. Oxford: Blackwells Scientific Publications. pp. 112-138.

Fredriksson K. and Kerridge J. F. 1988. Carbonates and sulfates in $\mathrm{Cl}$ chondrites - Formation by aqueous activity on the parent body. Meteoritics 23:35-44.

Füri E., Aleon-Toppani A., Marty B., Libourel G., and Zimmermann L. 2013. Effects of atmospheric entry heating on the noble gas and nitrogen content of micrometeorites. Earth and Planetary Science Letters 377:1-12.

Gao X. and Thiemens M. H. 1993. Isotopic composition and concentration of sulfur in carbonaceous chondrites. Geochimica et Cosmochimica Acta 57:3159-3169.

Geminale A., Formisano V., and Giuranna M. 2008. Methane in Martian atmosphere: Average spatial, diurnal, and seasonal behaviour. Planetary and Space Science 56:1194-1203.

Genge M. J. 2006. Igneous rims on micrometeorites. Geochimica et Cosmochimica Acta 70:26032621.

Genge M. J., Engrand C., Gounelle M., and Taylor S. 2008. The classification of micrometeorites. Meteoritics \& Planetary Science 43:497-515.

Genge M. J., Grady M. M., and Hutchison R. 1997. The textures and compositions of fine-grained Antarctic micrometeorites: Implications for comparisons with meteorites. Geochimica Et Cosmochimica Acta 61:5149-5162.

Gounelle M. and Zolensky M. E. 2001. A terrestrial origin for sulfate veins in $\mathrm{Cl} 1$ chondrites. Meteoritics \& Planetary Science 36:1321-1329.

Greshake A., Klock W., Arndt P., Maetz M., Flynn G. J., Bajt S., and Bischoff A. 1998. Heating experiments simulating atmospheric entry heating of micrometeorites: Clues to their parent body sources. Meteoritics \& Planetary Science 33:267-290.

Hayatsu R., Matsuoka S., Anders E., Scott R. G., and Studier M. H. 1977. Origin of organic matter in the early solar system. VII - the organic polymer in carbonaceous chondrites. Geochimica et Cosmochimica Acta 41:1325-1339.

Hayatsu R., Scott R. G., and Winans R. E. 1983. Comparative structural study of meteoritic polymer with terrestrial geopolymers coal and kerogen. Meteoritics 18:310-310.

Horsfield B. and Douglas A. G. 1980. The influence of minerals on the pyrolysis of kerogens. Geochimica et Cosmochimica Acta 44:1119-1131.

Howard K. T., Benedix G. K., Bland P. A., and Cressey G. 2009. Modal mineralogy of CM2 chondrites by X-ray diffraction (PSD-XRD). Part 1: Total phyllosilicate abundance and the degree of aqueous alteration. Geochimica et Cosmochimica Acta 73:4576-4589.

Howard K. T., Benedix G. K., Bland P. A., and Cressey G. 2011. Modal mineralogy of CM chondrites by $X$-ray diffraction (PSD-XRD): Part 2. Degree, nature and settings of aqueous alteration. Geochimica et Cosmochimica Acta 75:2735-2751.

Hyman M. and Rowe M. W. 1983. Magnetite in Cl chondrites. Journal of Geophysical Research 88:A736-A740. 
Imae N., Taylor S., and Iwata N. 2013. Micrometeorite precursors: Clues from the mineralogy and petrology of their relict minerals. Geochimica Et Cosmochimica Acta 100:116-157.

Kale B. B., Pande A. R., and Gokarn A. N. 1992. Studies in the carbothermic reduction of phosphogypsum. Metallurgical Transactions B-Process Metallurgy 23:567-572.

Krasnopolsky V. A. 2006. Some problems related to the origin of methane on Mars. Icarus 180:359367.

Krasnopolsky V. A., Maillard J. P., and Owen T. C. 2004. Detection of methane in the martian atmosphere: Evidence for life? Icarus 172:537-547.

Kurat G., Koeberl C., Presper T., Brandstatter F., and Maurette M. 1994. Petrology and geochemistry of Antarctic micrometeorites. Geochimica et Cosmochimica Acta 58:3879-3904.

L'Vov B. V. 2000. Mechanism of carbothermal reduction of iron, cobalt, nickel and copper oxides. Thermochimica Acta 360:109-120.

Lauretta D. S., Hua X., and Buseck P. R. 2000. Mineralogy of fine-grained rims in the ALH 81002 CM chondrite. Geochimica et Cosmochimica Acta 64:3263-3273.

Love S. G. and Brownlee D. E. 1991. Heating and thermal transformation of micrometeroids entering the Earth's atmosphere. Icarus 89:26-43.

Love S. G. and Brownlee D. E. 1993. A direct measurement of the terrestrial mass accretion rate of cosmic dust. Science 262:550-553.

Mackinnon I. D. R. and Zolensky M. E. 1984. Proposed structures for poorly characterized phases in C2M carbonaceous chondrite meteorites. Nature 309:240-242.

Matthewman R., Cotton L. J., Martins Z., and Sephton M. A. 2012. Organic geochemistry of late Jurassic paleosols (Dirt Beds) of Dorset, UK. Marine and Petroleum Geology 37:41-52.

Matthewman R., Martins Z., and Sephton M. A. 2013. Type IV kerogens as analogues for organic macromolecular materials in aqueously altered carbonaceous chondrites. Astrobiology 13:324-333.

Maurette M. 1998. Carbonaceous micrometeorites and the origin of life. Origins of Life and Evolution of the Biosphere 28:385-412.

$\mathrm{Mu}$ J. and Perlmutter D. D. 1981. Thermal decomposition of inorganic sulfates and their hydrates. Industrial \& Engineering Chemistry Process Design and Development 20:640-646.

Mullie F. and Reisse J. 1987. Organic matter in carbonaceous chondrites. Topics in Current Chemistry 139:85-117.

Murae T. 1995. Characterization of extraterrestrial high-molecular-weight organic matter by pyrolysis-gas chromatography mass-spectrometry. Journal of Analytical and Applied Pyrolysis 32:65-73.

Murae T. 1997. Structure of high-molecular carbonaceous compound in carbonaceous chondrites and formation of IR-spectroscopically similar compounds in the laboratory. In Life Sciences: Complex Organics in Space, edited by Raulin F. and Greenberg J. M. New York: Pergamon. pp. 1053-1057.

Naono H., Nakai K., Sueyoshi T., and Yagi H. 1987. Porous texture in hematite derived from goethite mechanism of thermal-decomposition of goethite. Journal of Colloid and Interface Science 120:439-450.

Nozaki W., Nakamura T., and Noguchi T. 2006. Bulk mineralogical changes of hydrous micrometeorites during heating in the upper atmosphere at temperatures below 1000 degrees C. Meteoritics \& Planetary Science 41:1095-1114.

Pearson V. K., Sephton M. A., Franchi I. A., Gibson J. M., and Gilmour I. 2006. Carbon and nitrogen in carbonaceous chondrites: Elemental abundances and stable isotopic compositions. Meteoritics \& Planetary Science 41:1899-1918.

Pearson V. K., Sephton M. A., Kearsley A. T., Bland P. A., Franchi I. A., and Gilmour I. 2002. Clay mineral-organic matter relationships in the early solar system. Meteoritics \& Planetary Science 37:1829-1833. 
Quirico E., Montagnac G., Rouzaud J. N., Bonal L., Bourot-Denise M., Duber S., and Reynard B. 2009. Precursor and metamorphic condition effects on Raman spectra of poorly ordered carbonaceous matter in chondrites and coals. Earth and Planetary Science Letters 287:185193.

Quirico E., Raynal P. I., and Bourot-Denise M. 2003. Metamorphic grade of organic matter in six unequilibrated ordinary chondrites. Meteoritics \& Planetary Science 38:795-811.

Scheidema M. N. and Taskinen P. 2011. Decomposition thermodynamics of magnesium sulfate. Industrial \& Engineering Chemistry Research 50:9550-9556.

Sephton M. A. 2002. Organic compounds in carbonaceous meteorites. Natural Product Reports 19:292-311.

Shimokawabe M., Furuichi R., and Ishii T. 1979. Influence of the preparation history of $\alpha-\mathrm{Fe}_{2} \mathrm{O}_{3}$ on its reactivity for hydrogen reduction. Thermochimica Acta 28:287-305.

Smykatz-Kloss W. 1974. Differential Thermal Analysis. Springer-Verlag, Berlin.

Song S. X., Jia F. F., and Peng C. S. 2014. Study on decomposition of goethite/siderite in thermal modification through XRD, SEM and TGA measurements. Surface Review and Letters 21.

Strydom C. A., Groenewald E. M., and Potgieter J. H. 1997. Thermogravimetric studies of the synthesis of CaS from gypsum, CaSO $4 \cdot 2 \mathrm{H}_{2} \mathrm{O}$ and phosphogypsum. Journal of Thermal Analysis 49:1501-1507.

Szydlik P. P. and Flynn G. J. 1992. The internal temperature profiles of large micrometeorites during atmospheric entry. Meteoritics 27:294-295.

Taylor S., Matrajt G., and Guan Y. B. 2012. Fine-grained precursors dominate the micrometeorite flux. Meteoritics \& Planetary Science 47:550-564.

Tomeoka K., McSween H. Y., Jr., and Buseck P. R. 1989. Mineralogical alteration of CM carbonaceous chondrites: A review. Antartic Meteorite Research 2:221.

Toppani A. and Libourel G. 2003. Factors controlling compositions of cosmic spinels: Application to atmospheric entry conditions of meteoritic materials. Geochimica et Cosmochimica Acta 67:4621-4638.

Toppani A., Libourel G., Engrand C., and Maurette M. 2001. Experimental simulation of atmospheric entry of micrometeorites. Meteoritics \& Planetary Science 36:1377-1396.

van der Merwe E. M., Strydom C. A., and Potgieter J. H. 1999. Thermogravimetric analysis of the reaction between carbon and $\mathrm{CaSO} 4 \cdot 2 \mathrm{H}_{2} \mathrm{O}$, gypsum and phosphogypsum in an inert atmosphere. Thermochimica Acta 341:431-437.

Wasson J. T., Boynton W. V., Chou C. L., and Baedecker P. A. 1975. Compositional evidence regarding influx of interplanetary materials onto lunar surface. Moon 13:121-141.

Webster C. R., Mahaffy P. R., Atreya S. K., Flesch G. J., Farley K. A., and Team M. S. L. S. 2013. Low upper limit to methane abundance on Mars. Science 342:355-357.

Webster C. R., Mahaffy P. R., Atreya S. K., Flesch G. J., Mischna M. A., Meslin P.-Y., Farley K. A., Conrad P. G., Christensen L. E., Pavlov A. A., Martin-Torres J., Zorzano M.-P., McConnochie T. H., Owen T., Eigenbrode J. L., Glavin D. P., Steele A., Malespin C. A., Archer P. D., Jr., Sutter B., Coll P., Freissinet C., McKay C. P., Moores J. E., Schwenzer S. P., Bridges J. C., NavarroGonzalez R., Gellert R., Lemmon M. T., and Team M. S. L. S. 2015. Mars atmosphere. Mars methane detection and variability at Gale crater. Science 347:415-7.

Weisberg M. K., Prinz M., Clayton R. N., and Mayeda T. K. 1993. The CR (Renazzo-type) carbonaceous chondrite group and its implications. Geochimica et Cosmochimica Acta 57:1567-1586.

West R. R. and Sutton W. J. 1953. Thermography of gypsum. Journal of the American Ceramic Society 37:221-224.

Zheng D., Lu H., Sun X., Liu X., Han W., and Wang L. 2013. Reaction mechanism of reductive decomposition of FGD gypsum with anthracite. Thermochimica Acta 559:23-31.

Zinner E. 1988. Interstellar cloud material in meteorites. In Meteorites in the Early Solar System, edited by Kerridge J. F. and Mathews M. S. Tucson: Univeristy of Arizona Press. pp. 956-983. 
Zolensky M., Barrett R., and Browning L. 1993. Mineralogy and composition of matrix and chondrule rims in carbonaceous chondrites. Geochimica et Cosmochimica Acta 57:3123-3148.

Zolensky M. E., Mittlefehldt D. W., Lipschutz M. E., Wang M. S., Clayton R. N., Mayeda T. K., Grady M. M., Pillinger C., and Barber D. 1997. CM chondrites exhibit the complete petrologic range from type 2 to 1. Geochimica et Cosmochimica Acta 61:5099-5115. 
Table 1. The yields of volatiles from single-component samples as produced by simulated ablation at $1300^{\circ} \mathrm{C}$ under helium.

\begin{tabular}{|c|c|c|c|c|c|c|c|c|c|c|c|}
\hline \multirow{3}{*}{ Material } & \multirow{3}{*}{$\begin{array}{c}\text { Mean } \\
\text { sample } \\
\text { mass (mg) }\end{array}$} & \multicolumn{10}{|c|}{ Volatile yields (wt.\%) } \\
\hline & & \multicolumn{2}{|c|}{ Water } & \multicolumn{2}{|c|}{$\begin{array}{l}\text { Carbon } \\
\text { dioxide }\end{array}$} & \multicolumn{2}{|c|}{$\begin{array}{l}\text { Carbon } \\
\text { monoxide }\end{array}$} & \multicolumn{2}{|c|}{ Methane } & \multicolumn{2}{|c|}{$\begin{array}{l}\text { Sulfur } \\
\text { dioxide }\end{array}$} \\
\hline & & Mean & $S D^{1}$ & Mean & SD & Mean & SD & Mean & SD & Mean & SD \\
\hline Type III kerogen & 9.9 & 6.6 & 0.3 & 1.0 & 0.1 & 2.9 & 0.1 & 1.2 & 0.0 & 0.3 & 0.0 \\
\hline Type IV kerogen \& GDB & 5.7 & 7.9 & 0.4 & 31.5 & 3.1 & n.d. & n.d. & n.d. & n.d. & n.d. & n.d. \\
\hline Goethite & 13.0 & 8.7 & 0.1 & 0.3 & 0.0 & n.d. & n.d. & n.d. & n.d. & n.d. & n.d. \\
\hline Iron (III) oxide dihydrate & 12.2 & 14.0 & 0.1 & 3.4 & 0.0 & n.d. & n.d. & n.d. & n.d. & n.d. & n.d. \\
\hline Magnetite & 12.5 & 2.9 & 0.1 & 0.2 & 0.1 & n.d. & n.d. & n.d. & n.d. & n.d. & n.d. \\
\hline Olivine & 13.0 & 1.5 & 0.1 & 0.2 & 0.0 & n.d. & n.d. & n.d. & n.d. & n.d. & n.d. \\
\hline Serpentinite & 12.6 & 13.9 & 0.4 & 0.2 & 0.0 & n.d. & n.d. & n.d. & n.d. & n.d. & n.d. \\
\hline Iron (II) sulfide & 12.0 & 0.6 & 0.1 & 0.1 & 0.1 & n.d. & n.d. & n.d. & n.d. & n.d. & n.d. \\
\hline Calcium sulfate dihydrate & 11.8 & 20.6 & 1.1 & 0.2 & 0.0 & n.d. & n.d. & n.d. & n.d. & n.d. & n.d. \\
\hline Magnesium sulfate heptahydrate & 13.4 & 45.8 & 2.4 & 0.1 & 0.0 & n.d. & n.d. & n.d. & n.d. & 1.6 & 0.2 \\
\hline Sodium sulfate & 11.3 & 0.6 & 0.1 & 0.1 & 0.0 & n.d. & n.d. & n.d. & n.d. & 0.2 & 0.0 \\
\hline Calcium carbonate & 11.6 & 0.4 & 0.0 & 25.2 & 1.0 & n.d. & n.d. & n.d. & n.d. & n.d. & n.d. \\
\hline Magnesium carbonate BH & 11.4 & 20.6 & 1.5 & 27.3 & 0.3 & n.d. & n.d. & n.d. & n.d. & n.d. & n.d. \\
\hline
\end{tabular}

${ }^{1} \mathrm{SD}$ denotes standard deviation. Means and standard deviations were produced from three analyses. 
Table 2. The yields of volatiles from mixtures of two components as produced by simulated ablation at $1300^{\circ} \mathrm{C}$ under helium.

\begin{tabular}{|c|c|c|c|c|c|c|c|c|c|c|c|c|}
\hline \multirow{3}{*}{ Mixture components } & \multirow{2}{*}{\multicolumn{2}{|c|}{$\begin{array}{l}\text { Mean component } \\
\text { mass }(\mathrm{mg})\end{array}$}} & \multicolumn{10}{|c|}{ Volatile yields (wt.\%) } \\
\hline & & & \multicolumn{2}{|c|}{ Water } & \multicolumn{2}{|c|}{$\begin{array}{l}\text { Carbon } \\
\text { dioxide }\end{array}$} & \multicolumn{2}{|c|}{$\begin{array}{c}\text { Carbon } \\
\text { monoxide }\end{array}$} & \multicolumn{2}{|c|}{ Methane } & \multicolumn{2}{|c|}{$\begin{array}{l}\text { Sulfur } \\
\text { dioxide }\end{array}$} \\
\hline & Kerogen & Mineral & Mean & $\mathrm{SD}^{1}$ & Mean & SD & Mean & SD & Mean & SD & Mean & SD \\
\hline \multicolumn{13}{|l|}{ Type III kerogen \& } \\
\hline Goethite & 6.3 & 5.6 & 11.1 & 0.5 & 2.7 & 0.2 & 6.3 & 0.2 & 0.4 & 0.0 & 0.1 & 0.0 \\
\hline Iron (III) oxide dihydrate & 5.8 & 5.4 & 14.3 & 0.3 & 6.6 & 0.3 & 8.2 & 0.5 & 0.4 & 0.0 & 0.1 & 0.0 \\
\hline Magnetite & 5.6 & 6.7 & 9.3 & 0.6 & 4.3 & 1.0 & 5.5 & 2.2 & 0.4 & 0.0 & n.d. & n.d. \\
\hline Olivine & 6.0 & 6.2 & 5.7 & 0.7 & 0.7 & 0.0 & 1.6 & 0.1 & 0.5 & 0.0 & n.d. & n.d. \\
\hline Serpentinite & 6.8 & 6.9 & 10.6 & 1.2 & 0.8 & 0.1 & 2.1 & 0.1 & 0.6 & 0.0 & 0.2 & 0.0 \\
\hline Iron (II) sulfide & 6.5 & 6.5 & 5.4 & 1.0 & 0.7 & 0.1 & 1.5 & 0.2 & 0.6 & 0.0 & 0.4 & 0.1 \\
\hline Calcium sulfate dihydrate & 6.4 & 5.9 & 15.3 & 0.1 & 9.6 & 1.2 & 3.7 & 1.8 & 0.6 & 0.0 & 1.5 & 0.2 \\
\hline Magnesium sulfate heptahydrate & 6.8 & 6.9 & 26.9 & 1.3 & 5.2 & 0.7 & 3.6 & 0.3 & 0.6 & 0.0 & 5.3 & 0.7 \\
\hline Sodium sulfate & 5.7 & 6.0 & 7.0 & 1.1 & 13.9 & 5.2 & 7.6 & 1.0 & 0.6 & 0.0 & 2.9 & 0.6 \\
\hline Calcium carbonate & 6.1 & 7.3 & 6.9 & 0.9 & 15.6 & 1.2 & 8.6 & 0.7 & 0.4 & 0.0 & 0.3 & 0.1 \\
\hline Magnesium carbonate BH & 7.0 & 6.0 & 14.1 & 0.2 & 20.3 & 0.5 & 3.4 & 0.1 & 0.5 & 0.0 & n.d. & n.d. \\
\hline \multicolumn{13}{|l|}{ Type IV kerogen/GDB \& } \\
\hline Goethite & 5.4 & 5.8 & 7.9 & 0.2 & 17.4 & 1.9 & n.d. & n.d. & n.d. & n.d. & n.d. & n.d. \\
\hline Iron (III) oxide dihydrate & 6.0 & 5.6 & 11.4 & 0.4 & 18.2 & 0.6 & n.d. & n.d. & n.d. & n.d. & n.d. & n.d. \\
\hline Magnetite & 6.4 & 6.9 & 4.9 & 0.3 & 16.4 & 0.4 & n.d. & n.d. & n.d. & n.d. & n.d. & n.d. \\
\hline Olivine & 6.3 & 6.2 & 3.7 & 0.0 & 19.1 & 0.1 & n.d. & n.d. & n.d. & n.d. & n.d. & n.d. \\
\hline Serpentinite & 6.7 & 7.0 & 10.2 & 0.3 & 17.5 & 0.6 & n.d. & n.d. & n.d. & n.d. & n.d. & n.d. \\
\hline Iron (II) sulfide & 6.1 & 6.3 & 3.3 & 0.3 & 18.7 & 1.0 & n.d. & n.d. & n.d. & n.d. & 0.1 & 0.0 \\
\hline Calcium sulfate dihydrate & 6.4 & 6.1 & 13.0 & 0.3 & 21.2 & 0.3 & n.d. & n.d. & n.d. & n.d. & 1.7 & 0.3 \\
\hline Magnesium sulfate heptahydrate & 6.0 & 5.8 & 23.4 & 1.3 & 24.3 & 0.5 & n.d. & n.d. & n.d. & n.d. & 3.9 & 1.3 \\
\hline Sodium sulfate & 6.0 & 6.2 & 3.8 & 0.1 & 20.1 & 0.5 & n.d. & n.d. & n.d. & n.d. & 1.5 & 0.3 \\
\hline Calcium carbonate & 6.9 & 6.3 & 3.7 & 0.1 & 28.2 & 2.5 & n.d. & n.d. & n.d. & n.d. & n.d. & n.d. \\
\hline Magnesium carbonate $\mathrm{BH}$ & 6.9 & 6.4 & 13.7 & 0.4 & 43.1 & 0.7 & n.d. & n.d. & n.d. & n.d. & n.d. & n.d. \\
\hline
\end{tabular}

${ }^{1} \mathrm{SD}$ denotes standard deviation. Means and standard deviations were produced from three analyses. 
Page 29 of 31

Meteoritics \& Planetary Science

Figure 1

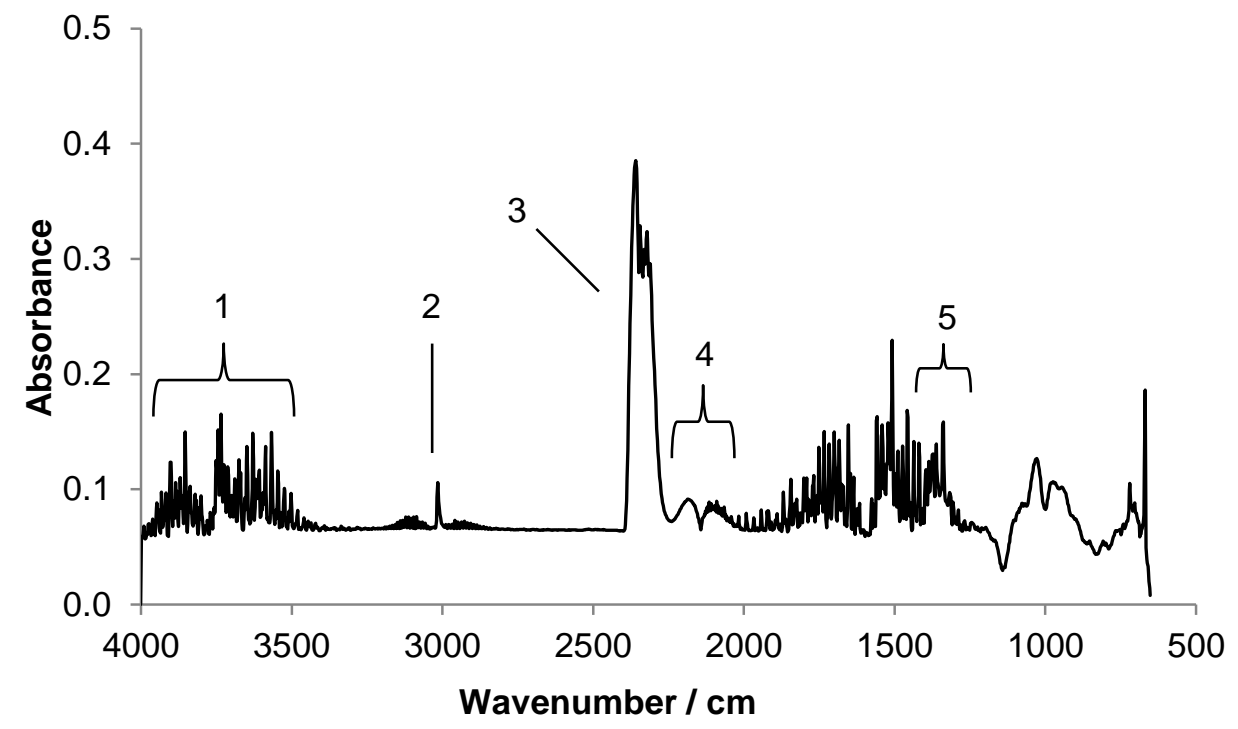


Figure 2

A) Water

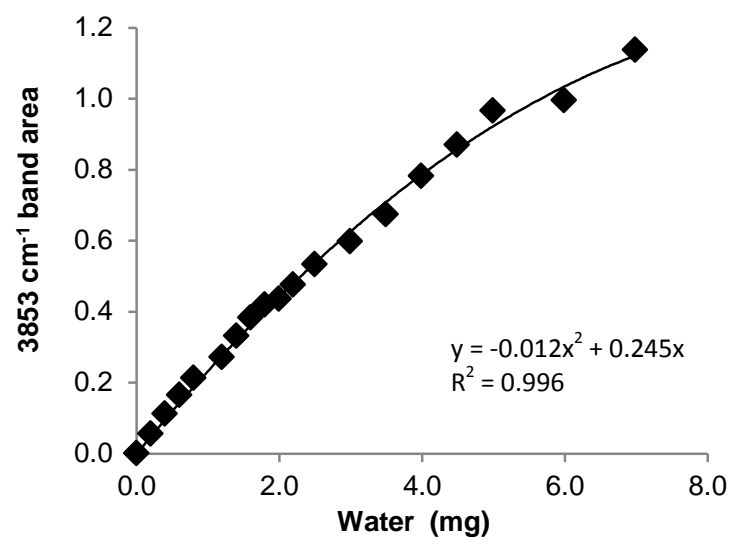

C) Sulphur dioxide

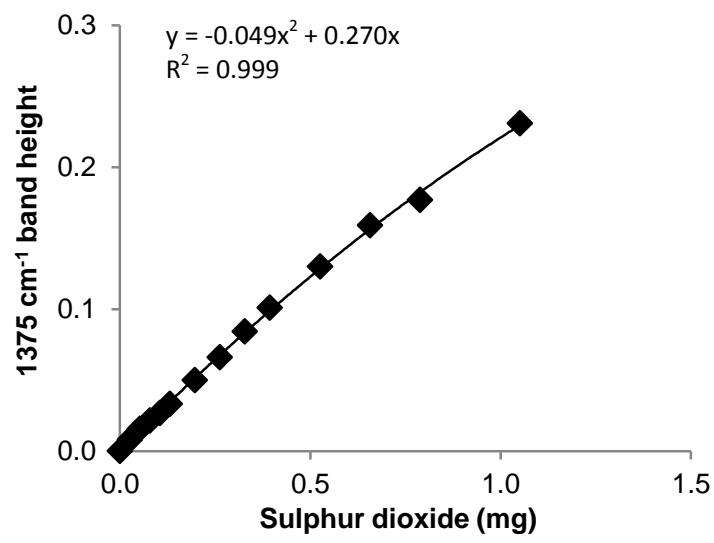

E) Methane

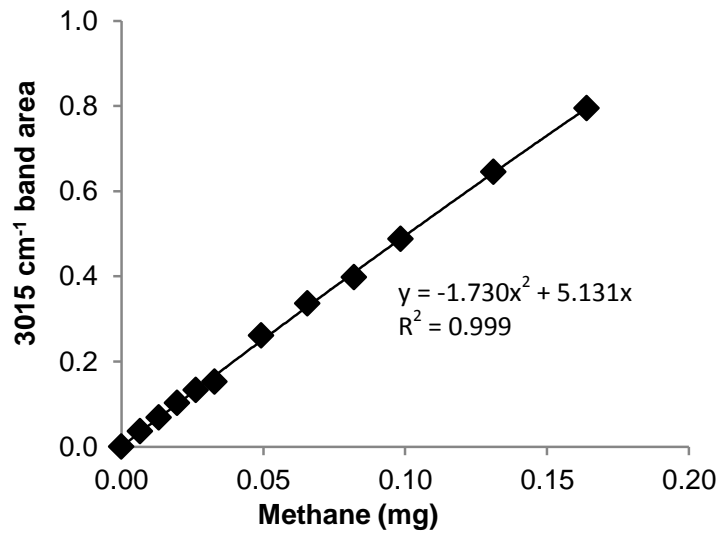

B) Carbon dioxide

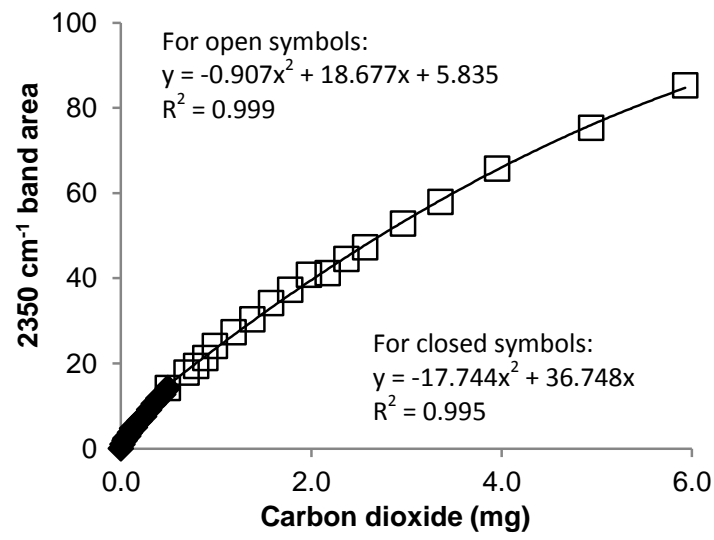

D) Carbon monoxide

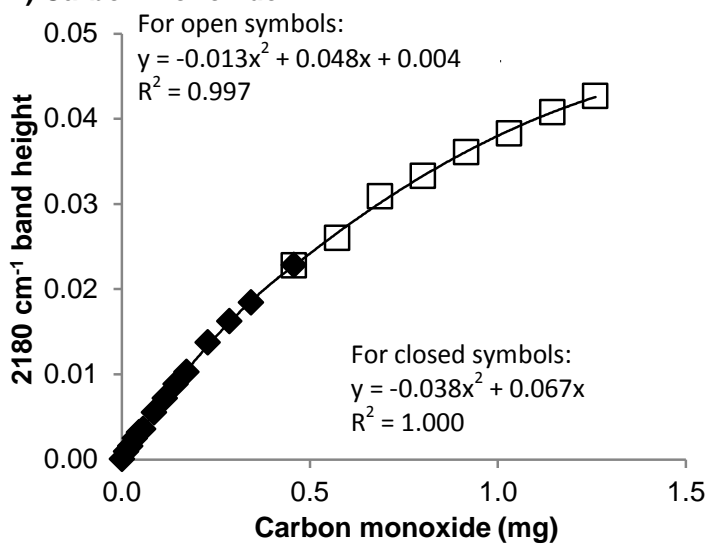


Figure 3
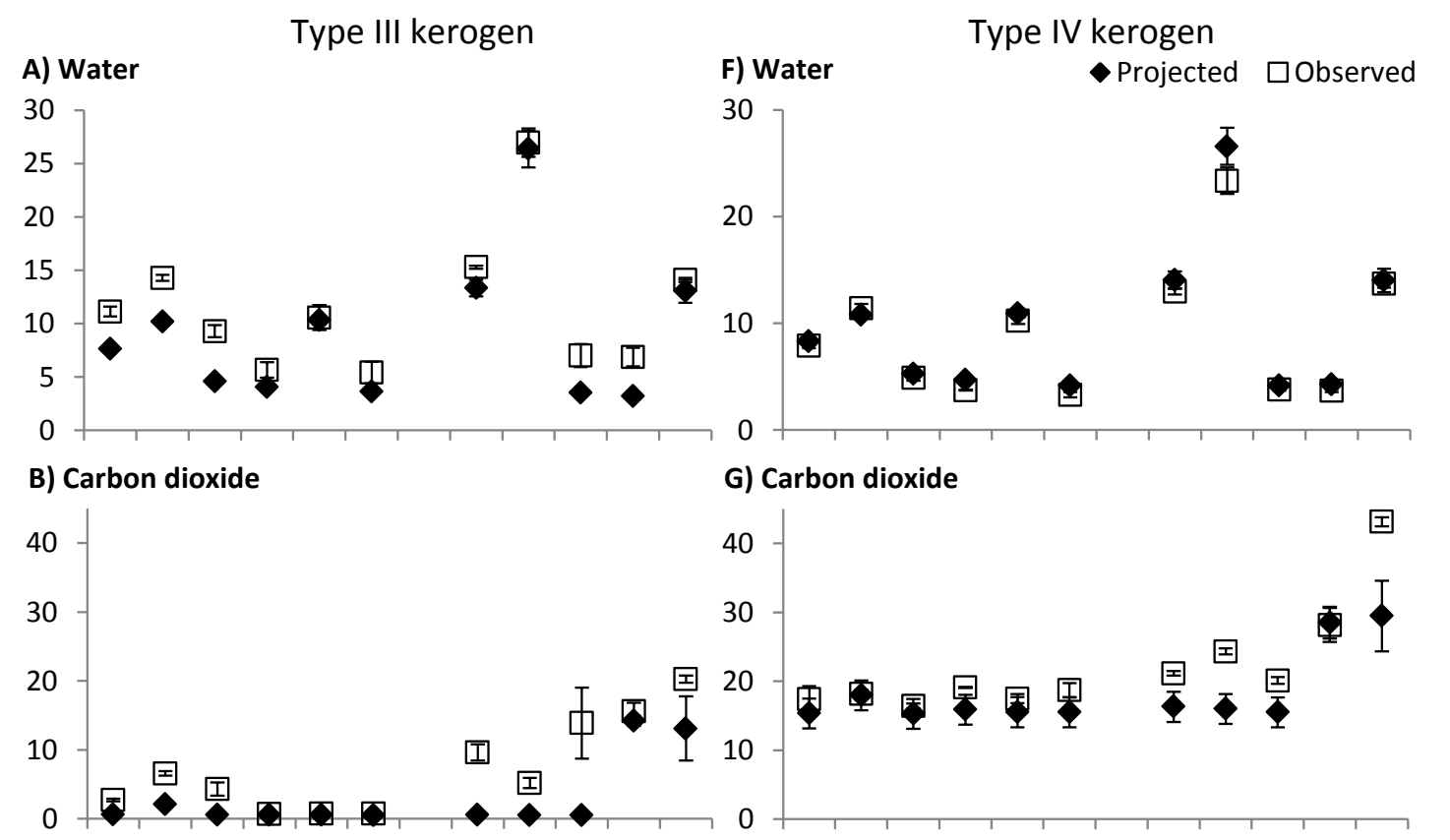

C) Carbon monoxide

H) Carbon monoxide

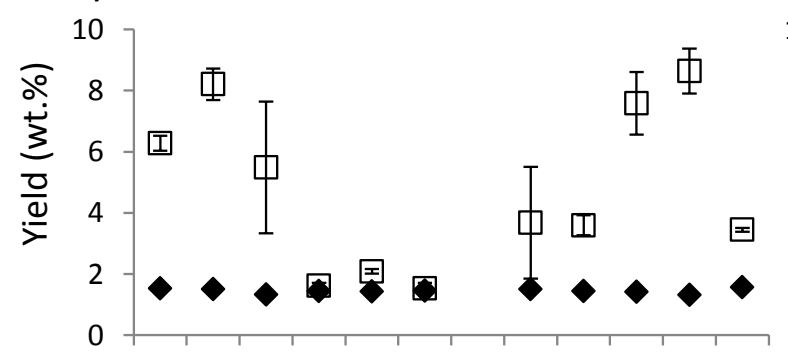

10

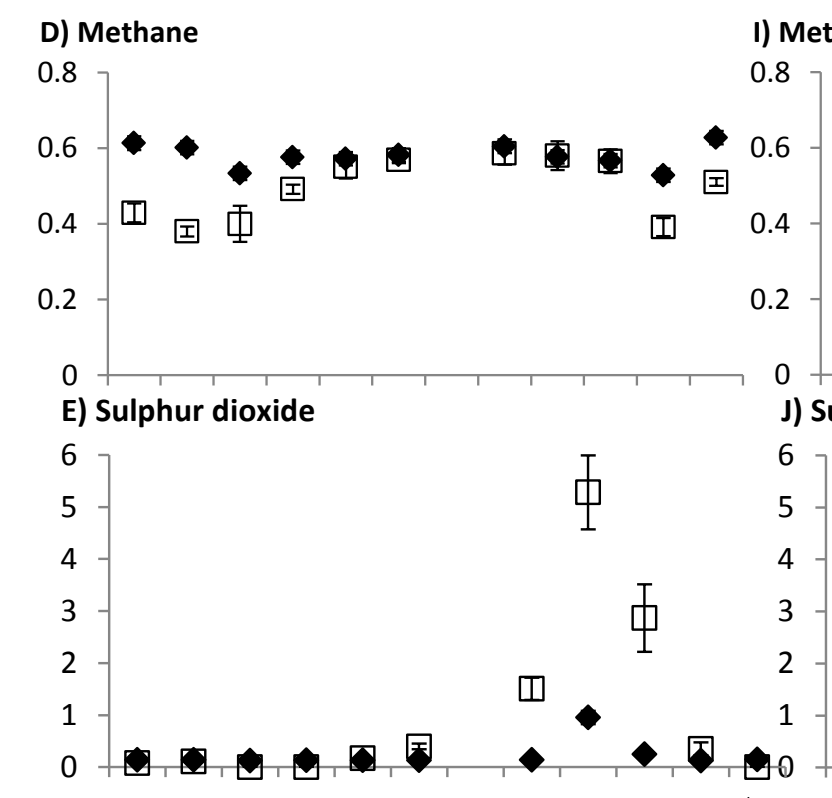

Methane

$\theta, \theta, \theta, \theta$

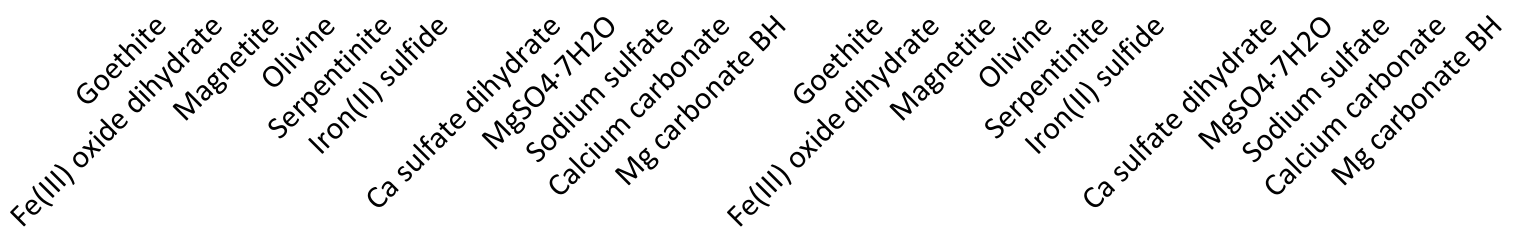

